\title{
Sidewalk design in multi-cultural settings: a study of street furniture layout and design
}

\author{
Maryam Lesan ${ }^{1} \cdot$ Morten Gjerde ${ }^{2}$
}

Published online: 23 March 2020

(c) Springer Nature Limited 2020

\begin{abstract}
Public space, and all the complexities surrounding its creation and management, continues to be the domain of urban designers. In multi-cultural societies, the users of public space come from a diverse range of social and ethnic backgrounds, each with some unique needs and interests. Because of this, it can be assumed that social, cultural, and economic characteristics of people living in an area should be evident in the design and use of the public spaces. The research reported in this paper identifies the sidewalk design characteristics and furniture arrangements that can foster social activities amongst people from diverse cultural backgrounds. The research followed a mixed, multi-staged methodology. Stage one used structured field observations and surveys of street users. Three suburban centre streets in two New Zealand cities were studied in this way to understand the patterns of usage along their length. Stage two sought people's preferences for different street design configurations through an on-line survey. The main conclusion from this research is that the seating preferences of different ethnicities are in many ways similar. However, people make specific decisions on where to sit based on the location, orientation and arrangement of seating and how it relates to different land-use activities. The findings confirm that a complex set of factors influence social activity along streets and that, in light of this, designers should become familiar with the diverse needs and expectations of those who make use of the sidewalks.
\end{abstract}

Keywords Street furniture $\cdot$ Sidewalks $\cdot$ Social activity $\cdot$ Multi-culturalism

\section{Introduction}

The different ways people make use of public space has intrigued urban planners and designers for some time. From providing an arena for political representation to performing symbolic and representative functions, public spaces represent vital roles in the public life and cultural vitality of cities (Pugalis 2009). High quality public spaces are recognised as a precondition for economic health, development and competitiveness of cities (Carmona et al. 2008). Public spaces can also help foster a sense of community and mutual trust between users, according to the values and norms that are shared about them within the community (Madanipour

Maryam Lesan

m.lesan@nit.ac.ir; lesanmary@gmail.com

1 Noshirvani University of Technology, Shariati Av., Babol, Mazandaran 47148 - 71167, Iran

2 Faculty of Architecture and Design, Victoria University of Wellington, 139 Vivian St., Te Aro, Wellington 6011, New Zealand
2004; Mulgan et al. 2006; Pugalis 2009). Most importantly, public spaces offer a ground for sociability, becoming a setting for unplanned communications and social interactions both between friends/family members and strangers (Kohn 2004; Mehta 2013; Thomas 1991; Varna and Tiesdell 2010).

In cities with diverse ethnic populations, public spaces are also becoming intercultural places, where people from different cultures and ethnicities can meet and interact with each other (Hou 2013; Mehta 2013; Velden and Reeves 2010). One of the basic assumptions of Western multi-cultural democratic societies is that every person has the right to equitable access and enjoyment of public spaces (Thompson 2003). This coincides with the democratic nature of public spaces. With increasing cultural diversity, the chances that different cultures will share a city's public spaces have also increased. Good quality public spaces are known as spaces "where ethnically and culturally diverse groups can co-exist peacefully" (Mulgan et al. 2006, p. 28). Around the world, designers are becoming aware that public spaces should do more than meet the needs of the dominant culture (Carmona 2019). Design outcomes that are focussed on the 
values of a single culture may not meet the needs and values of other cultures, thereby negatively affecting people's use and enjoyment.

In multi-cultural societies, public space design can be challenging as people with diverse ethnic, age and socioeconomic backgrounds may have special requirements for their preferred activities (Carr et al. 1992). In addition, the signs and symbols evident in public spaces, whether overt or nuanced, can convey different meanings to the different cultures that use them (Rapoport 1982). The different needs and expectations people have for the public spaces they visit makes it important that complex design decisions are based on clear evidence. There is, however, a paucity of empiric evidence for the public space needs of different ethnic cultures and even fewer that investigate the role furniture plays in these settings. The questions driving this research consider the influences that layout, design and management of street furniture could have on people's stationary and social activities, with the associated aim of encouraging streets to be used by people coming from the different ethnic cultures that live in the surrounding area.

\section{Streets and their sidewalks}

Rather than simply acting as movement corridors for vehicular traffic, streets can also be conceived of as social spaces. Indeed, streets influence the quality of social life (Appleyard 1981; Jacobs 1961, 1993; Mehta 2013). Simple activities, such as walking, talking, people watching, and eating help to create diversity in the life of streets (Francis 1987). Streets also provide opportunities for people to encounter similarities and differences, to discover different points of view, and perhaps resolve conflicts as they arise (Mehta 2013). Great streets encourage sociability by fostering interactions between people (Gehl 1987). The question then arises; how can sidewalk spaces be designed to create these opportunities for increasingly multi-cultural populations?

\section{Street furniture and sociability}

Furniture, ranging from fixed and temporary seating to streetlamps and rubbish bins, is an important component of outdoor spaces. In addition to supporting specific activities, furniture contributes to the aesthetic landscape of a street. Seating, in particular, is seen to be a critical factor in the perceived quality of public spaces, helping to promote positive social use (Hass-Klau et al. 1999; Main and Hannah 2010; Shaftoe 2009). Whyte's (1980) studies of small spaces in New York turned mainly on the relative numbers of people using public spaces, on the basis that density of use is the key measure of success. It follows then that seating

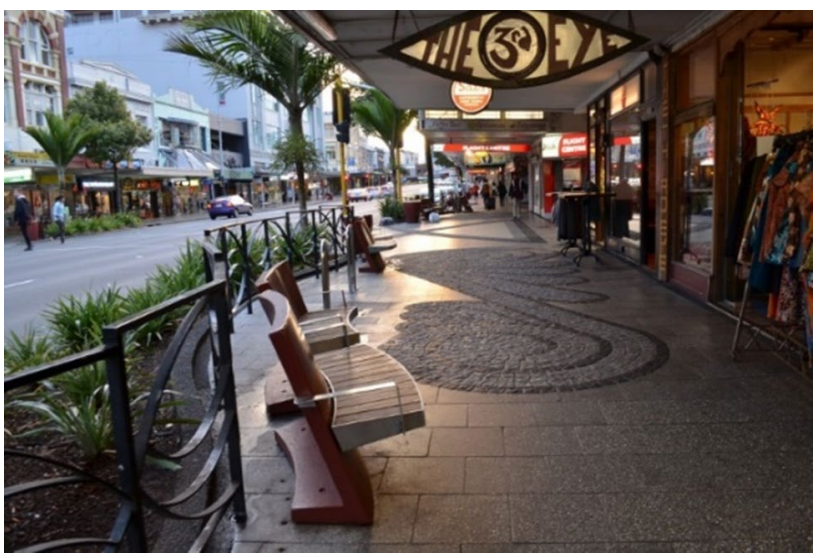

Fig. 1 Furniture along a street in Auckland, New Zealand. Furniture is sometimes selected on the grounds of aesthetic appearance rather than on how it might meet the broader needs of users

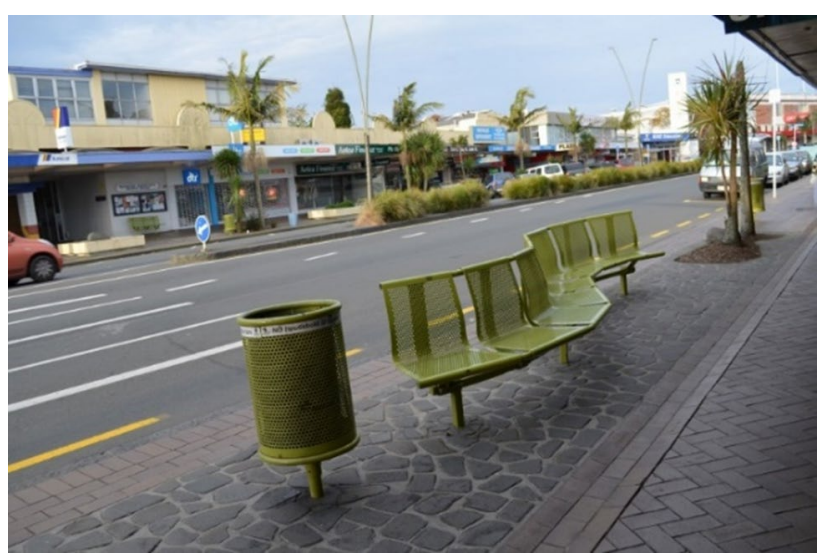

Fig. 2 Placing furniture along sidewalks does not guarantee that it will be used

which supports social interaction is a relevant success factor (Joardar and Neill 1978; Porta and Luciano 2005; Whyte 1980) (Figs. 1, 2).

While it is clear that furniture plays an important role in people's experiences, in many cases this has been undervalued in public space design processes. Hass-Klau et al. (1999) indicated that the location of seating is an important factor that can both encourage or discourage social interaction and the Project for Public Spaces noted that "seating that is accessible, comfortable, well-maintained, and located in the right places is critical to successful place-making" (PPS 2008b). However, when furniture is specified, more often than not the decisions are based on aesthetic appearance rather than on the ways it might meet pragmatic needs of the user, such as ergonomics and comfort. Once street furniture is selected for use in a city, it is often then used repeatedly to rationalise procurement, installation and maintenance costs. Whenever furniture is deployed on these grounds, it 
may not achieve the potential it has to support social activities, particularly amongst the range of different backgrounds and potential different interests and needs. This has also led to many public spaces that are "littered with seating of the wrong type, in the wrong place, with the result that is rarely used" (Shaftoe 2009, p. 93).

Several theories inform the configuration of seating, including prospect and refuge theory and proxemics. Prospect and refuge theory has its foundations in the behaviour of the first humans on the African savannah, explaining that people prefer vantage points at the edges of a large space, where views are expansive and where they can feel protected from being approached from behind (Appleton 1975). Humans also prefer settings that provide cover or other forms of shelter in comparison with unshielded spaces. For example, an area containing trees is preferred to a treeless setting, as it provides opportunities to escape from possible threats.

People behave and interact differently in different settings based on their socio-culturally defined personal space. The concept of proxemics was developed by Hall (1966) in his book The Hidden Dimension, to explain how personal space is culturally defined and has different standards among people with different cultural backgrounds. This is most clearly evident in the distance people take from others they are engaged in conversation with. In some cultures, these distances are commonly quite small while in others, such as Anglo-American and northern European, people tend to prefer more generous distances between each other. In addition to cultural background, other factors such as socio-economic status, gender, individual preference and different situations can influence the personal separation distances that people feel comfortable with (Hall 1966; Main and Hannah 2010).

Public spaces that accommodate variations in the ways people orient themselves to others will be used by a more diverse range of people (Joardar and Neill 1978; Main and Hannah 2010). Furniture arrangements could encourage or discourage face-to-face communication. The terms 'sociopetal' and 'socio-fugal' were coined by Humphrey Ostmond (1957) to describe arrangements that are expected to bring people together or set them apart. Socio-petal configurations orient users towards each other and encourage face-to-face communication. Socio-fugal arrangements place people away from one another to discourage face-to-face interactions (Fig. 3). On the other hand, such arrangements tend to encourage individuals to use public spaces (Kaye and Murray 1982; Lang 1987; Main and Hannah 2010). Culture also influences the ways people engage with others. For example, Latin Americans prefer to sit side by side for informal conversations whereas Anglo-Americans prefer to engage in face-to-face conversation (Hall 1966; Lang 1987). It has also been noted that people from different ethnic and cultural backgrounds tolerate different levels of density and noise in public space and that this can also influence seating location preferences (Main and Hannah 2010).

Previous studies about streets have tended to separate the physical aspects of the environment from the use and management of the businesses along them (Mehta 2013). However, “ ... it remains difficult to isolate physical features from social and economic activities that bring value to our experiences..." (Jacobs 1993 as cited in Mehta 2013). Social activities take place in relation to the physical attributes of streets and the activities found along them. In this vein, Parham (2012) explores how the relationships between physical design and food-oriented social practices can stimulate vibrancy in urban settings. Thompson (2003) considers the ways in which different groups use public space as consumption space is an important aspect that planners need to address in multi-cultural milieus. Food and eating practices are commonly seen as appropriate examples of cultural distinction that in turn lead to cultural communication and ethnic bonding (Rapoport 2005). Familiar recipes, tastes and smells often help create a sense of social and cultural belonging in a foreign environment for immigrants (Thompson 2003; Zambonelli 2013). Aligned to this are the relationships that exist between seating and food practices.

The design of building facades along the length of a street and relationships between them have considerable influence on how the street is perceived (Gjerde 2011). Street edges in commercial centres generally comprise a
Fig. 3 Left: socio-petal seating (inward-facing); right: Sociofugal seating (outward-facing). Redrawn from Main and Hannah (2010, p. 27)
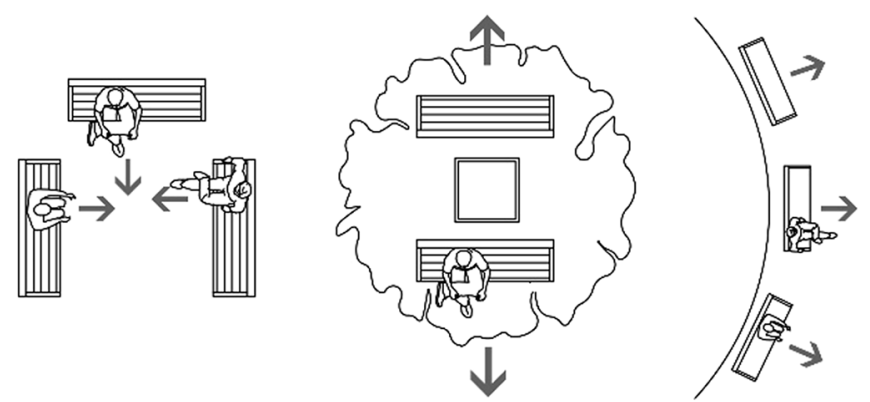
mixture of shop fronts to diverse retail, commercial, food and other businesses as well as entries to offices and apartments on the upper floors. The ways shops display goods on their frontages, extent of visual permeability (façade transparency), the visual complexity of buildings, shop fronts, and window decorations will all influence people's preferences, and therefore, the behavioural choices they make as they move along a street (Fernando 2006; Mehta 2013; Rapoport 2008). Some businesses extend their merchandise onto the sidewalk creating a shopping opportunity for some, causing them to slow and linger as they pass (Mehta 2006; Whyte and Underhill 1988). This project was also designed to examine the effects that shop front design can have on street-based social activities.

\section{Research methodology}

The research was undertaken in two stages (Fig. 4) with information collected about the use of streets by people from European, Māori, Pacific Island and Asian ethnic cultures. The rationale for focussing on these groups is that they were identified in the most recent census of New Zealanders as the four largest (Pearson 2012).

\section{Stage one: the ethnographic fieldwork}

The first stage of the fieldwork employed structured field observations using a behavioural mapping procedure and open-ended interviews of users of the streets. This stagegenerated information about how street furniture was being used by the public and people's reasons for using them in these ways.

Three streets, two in Auckland and one in Wellington, were selected based on the population mix of the suburb they run through. The first of these is Riddiford Street in Newtown, the most ethnically diverse area of Wellington but one where Europeans are still the most common. The second is St George Street in Papatoetoe, an Auckland neighbourhood centre with an even balance between the four ethnic groups. The third was Great South Road in Otahuhu, which has a large Pacific Island population (Fig. 5).

Behavioural mapping has been used effectively to document people's race/ethnicity in studies of urban parks (Cohen et al. 2007; Hutchinson 1987; Loukaitou-Sideris 1995). The researchers adopted a similar approach in visually identifying a person's ethnic background in the process of documenting their behaviour. Codes were developed for the four ethnicities and a fifth, acting as a catch-all for those not identified with these. Where the observer was not confident about a person's ethnic background, such as one of

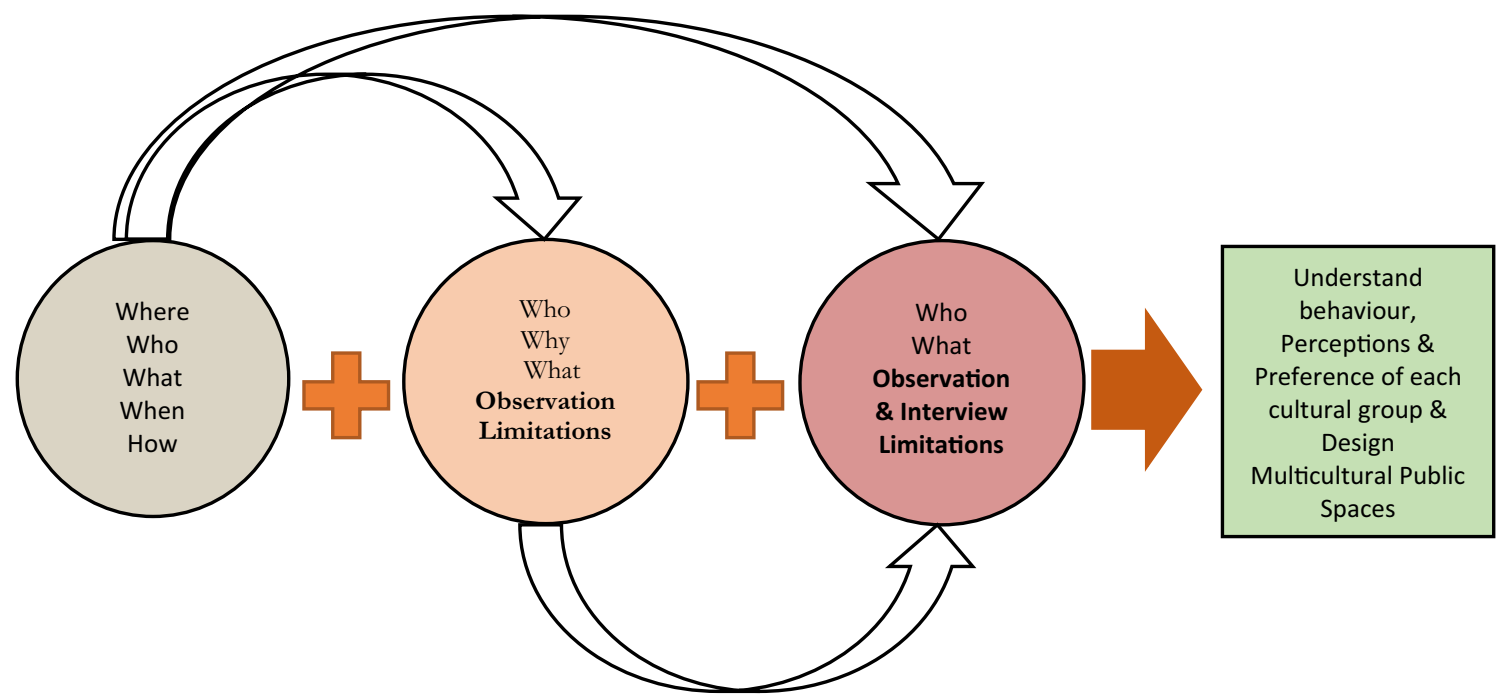

$\begin{array}{lll}\text { OBSERVATION INTERVIEW } & \text { VPS }\end{array}$

\section{STAGE ONE}

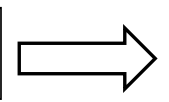

STAGE TWO

Fig. 4 Observations, interviews and visual preference surveys create comprehensive and robust data and help shape how we design public spaces in multi-cultural societies. Stage One's diagram is adapted from Mehta's (2006) diagram on "Lively Streets" 


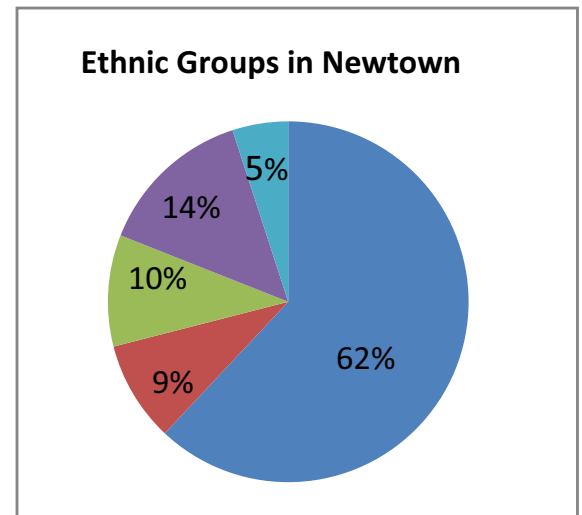

European
Ethnic Groups in Papatotoe

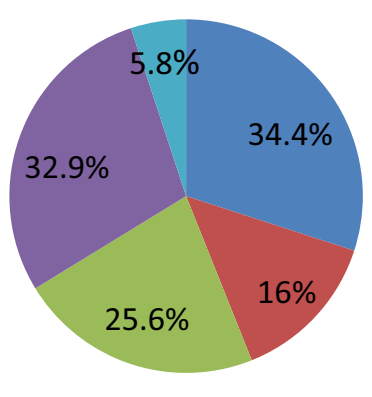

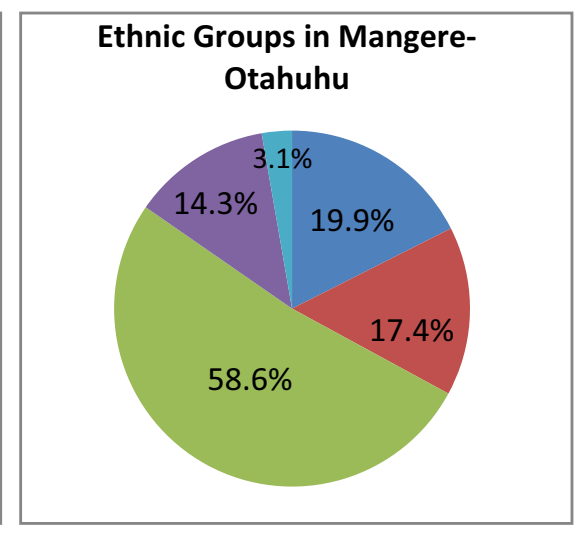

Other Ethnicity

Pacific Peoples $\quad$ Asian

Maori

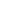

Fig. 5 Ethnic composition of the studied neighbourhoods

Table 1 Number of total observations (TO), interviews (I) and different cultural groups using public benches (SO) in different streets

\begin{tabular}{|c|c|c|c|c|c|c|c|c|c|c|c|c|}
\hline \multirow{2}{*}{$\begin{array}{l}\text { Case study } \\
\text { Cultural background }\end{array}$} & \multicolumn{3}{|c|}{ Riddiford Street } & \multicolumn{3}{|c|}{ St George Street } & \multicolumn{3}{|c|}{ Great South Road } & \multicolumn{3}{|l|}{ Total } \\
\hline & TO & I & $\mathrm{SO}$ & TO & I & SO & TO & I & SO & TO & I & $\mathrm{SO}$ \\
\hline European & 820 & 9 & 148 & 107 & 5 & 23 & 122 & 2 & 31 & 1049 & 16 & 202 \\
\hline Māori/Pacific Islanders & 332 & 15 & 80 & 410 & 13 & 136 & 1806 & 18 & 345 & 2548 & 46 & 561 \\
\hline Asian & 163 & 6 & 32 & 299 & 9 & 103 & 611 & 8 & 63 & 1073 & 23 & 198 \\
\hline Other & 86 & - & 35 & 13 & - & 2 & 15 & - & 2 & 114 & - & 39 \\
\hline Total & 1401 & 30 & 295 & 829 & 27 & 264 & 2554 & 28 & 441 & 4784 & 85 & 1000 \\
\hline
\end{tabular}

mixed-race, they were coded in the 'Other' category. During observations, it was recognised that distinguishing between Māori and Pacific Islanders was difficult, thus people identified as one or the other were coded under a single combined heading in this part of the fieldwork. Users' ages or genders were also recorded for future analysis, although this was seen as a secondary interest relative to people's ethnic backgrounds.

Walk-by observations were conducted every hour between 10:00 AM and 6:00 PM on weekdays and weekends within each case study area. This resulted in 24 (equivalent to 3 days) weekday observations and 16 (equivalent to 2 days) weekend observations for each. Data were collected on days with varying cloud cover and wind conditions. There were no observations made during periods of rain. The average temperature varied between $15^{\circ}$ and $20^{\circ} \mathrm{C}$ in observation hours.

Only those activities that took place on public seating were noted. Of 1401 behaviours mapped along Riddiford Street, 295 people were sitting on public benches. Similarly, 264 out of 829 recorded activities on St George Street and 441 out of 2554 activities on Great South Road were documented on public benches.

The semi-structured and open-ended interviews were designed as a kind of flexible and broad survey. The questions did not focus on any specific design criteria such as seating. On the other hand, the interviews examined participants' activities on the street, the places they chose for their activities and the reasons they chose those places. Participants' suggestions for improving the street environment were of interest to the researchers to be able to understand the principal requirements of people in each cultural grouping. Interviews were conducted at various times of the day and different days of the week to include a representative sample. The researchers sought to recruit interview participants from a diverse range of ethnic groups. As such, approaches were made to people on the basis of their appearance and making personal judgement as to which ethnic group they may belong to. Those who were sitting, standing and otherwise appeared to be lingering along the sidewalks were approached. This addressed two key issues, one of which was availability. People who were lingering along the street were considered to not be in a rush, and therefore, to have more time to participate. More importantly, the research sought to understand the experiences of people who use the street and activities along for social and other purposes.

In total, 85 persons were interviewed: 16 European, 20 Māori, 26 Pacific Islander and 23 Asian. The responses 
were categorised and coded and analysed in relation to seating (Table 1).

\section{Analysis}

Activities taking place along sidewalks were categorised into three spatial zones; zone "A" is at the edge of the buildings and shop fronts and zone " $\mathrm{B}$ " is the primary channel for pedestrian movement. Zone " $\mathrm{C}$ " is not always available but where it is available, it is adjacent to the road and parked vehicles (Mehta 2006). This is the part of the sidewalk that is most often furnished with fixed benches, tree trunks, and litter bins. Shop advertising signage is often located in zone "A" (Fig. 6).

The number of people from each of the different ethnicities that were seated along the study area were logged and compared to the overall number of people involved in different stationary and social activities. These figures were also compared to the demographic characteristics of the neighbourhoods. The locations of various behaviours and different cultural groups were then analysed in relation to nearby sidewalk features and business activities to give an indication of how well each section of the street serves the needs of the different cultural groups.

\section{Patterns of occupancy of public seating}

The use of streets for stationary and social activities is mainly related to the opening hours of business activities. Benches went unused during observation times (after $4 \mathrm{pm}$ ) when these activities were closed. The extent to which benches were used by different ethnic groups reflected the overall profile of the visitors to the street. The numbers of visitors from each culture appeared to relate to the mix of business activities on offer more strongly than it did to the ethnic composition of the neighbourhood. For example, while many Europeans used a range of public and private seating along Riddiford Street, few Europeans were recorded using the seating along St George Street or Great South
Road, as the adjacent business activities did not appeal to this particular ethnic culture (Lesan and Gjerde 2015).

Seated activities and the use of public and commercial seating in streets were also influenced by cultural attitudes and socio-economic status of street visitors. Māori/Pacific Islanders were the most frequent users of seating benches in all study areas. It is likely that the frequency with which Māori/Pacific Islander groups use public seating is related to income levels, as Loukaitou-Sideris (1995) suggests that those from lower socio-economic levels are more dependent on public spaces for recreation and social activities than those from more affluent groups. Māori and Pacific Islanders are overrepresented in the lower socio-economic classifications in New Zealand.

It started to become clear that the patterns and rhythms of use were influenced by adjacent businesses. The benches close to businesses that targeted specific ethnic groups and genders were frequently occupied by those groups. There also seemed to be differences between the groups' attitudes toward the street environment. Few Asians used public benches for eating/drinking whereas Pacific Islanders' social activities on the sidewalks were often associated with eating/ drinking (Table 2). For Europeans, eating/drinking while socialising was related to the setting; they were most often seen to socialise on café seating (Table 3 ). Therefore, providing a mixture of public and private seating along a street in a multi-cultural setting could encourage greater numbers of each ethnic culture to socialise there (Fig. 7).

What was common among all well used benches across the three cases was that all were located in the active sections of the street, surrounded by activity supporting businesses (independent shops with active frontages or with specific functions such as fast foods or bakeries). The attraction to business activities was reinforced by observations of people sitting on ledges and surfaces close to specific activities rather than on the furniture provided elsewhere. This could be explained by people sitting close to the activities they came to pursue. Another explanation could be that people tend to seek liveliness, activity and engagement while
Fig. 6 The three activity zones, adapted from Mehta, 2006

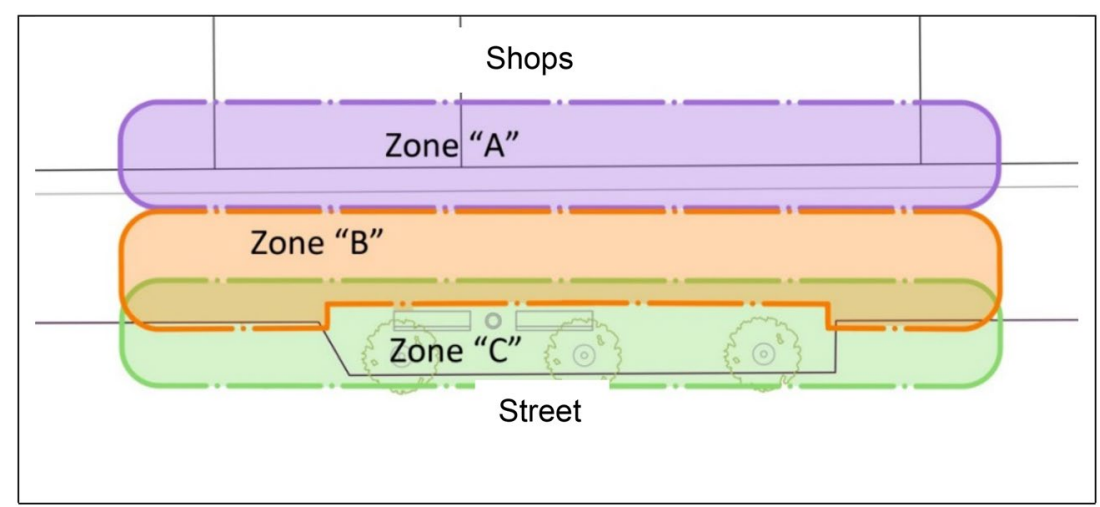


Table 2 Number of people of different cultures involved in different types of activities while seated both individually and in groups in the studied streets

\begin{tabular}{|c|c|c|c|c|c|c|c|c|c|c|c|}
\hline \multirow[t]{2}{*}{ Activity } & \multicolumn{11}{|c|}{ Cultural background } \\
\hline & $\mathrm{E} / \mathrm{I}$ & $\mathrm{E} / \mathrm{G}$ & $\mathrm{MP} / \mathrm{I}$ & $\mathrm{MP} / \mathrm{G}$ & $\mathrm{A} / \mathrm{I}$ & $\mathrm{A} / \mathrm{G}$ & $\mathrm{O} / \mathrm{I}$ & $\mathrm{O} / \mathrm{G}$ & Total/I & Total/G & Total \\
\hline \multicolumn{12}{|l|}{ Riddiford Street } \\
\hline Sitting/people watching & 77 & 16 & 37 & 2 & 9 & 10 & 11 & 6 & 134 & 34 & 168 \\
\hline Sitting and talking & 0 & 57 & 0 & 31 & 0 & 12 & 0 & 15 & 0 & 115 & 115 \\
\hline Sitting, talking and eating & 0 & 90 & 0 & 12 & 0 & 1 & 0 & 0 & 0 & 103 & 103 \\
\hline Sitting and eating & 18 & 11 & 11 & 3 & 2 & 0 & 2 & 0 & 33 & 14 & 47 \\
\hline Sitting and smoking & 19 & 2 & 6 & 3 & 1 & 0 & 1 & 0 & 27 & 5 & 32 \\
\hline Sitting and reading/writing & 24 & 0 & 1 & 0 & 0 & 0 & 0 & 0 & 25 & 0 & 25 \\
\hline Sitting and mobile using & 12 & 0 & 2 & 0 & 1 & 0 & 1 & 0 & 16 & 0 & 16 \\
\hline Sitting, talking and smoking & 0 & 3 & 0 & 1 & 0 & 0 & 0 & 2 & 0 & 6 & 6 \\
\hline Other activities & 3 & 2 & 0 & 0 & 0 & 0 & 0 & 0 & 3 & 2 & 5 \\
\hline $\begin{array}{l}\text { Total number of seated activities } \\
\text { (public and private) }\end{array}$ & 154 & 181 & 56 & 52 & 14 & 22 & 15 & 23 & 239 & 288 & 517 \\
\hline \multicolumn{12}{|l|}{ St George Street } \\
\hline Sitting/people watching & 10 & 0 & 39 & 17 & 21 & 15 & 0 & 0 & 69 & 32 & 102 \\
\hline Sitting and talking & 0 & 6 & 0 & 29 & 0 & 47 & 0 & 0 & 0 & 82 & 82 \\
\hline Sitting and eating/drinking & 2 & 0 & 5 & 17 & 3 & 0 & 1 & 0 & 11 & 17 & 28 \\
\hline Sitting and smoking & 0 & 0 & 1 & 2 & 2 & 2 & 0 & 0 & 3 & 4 & 7 \\
\hline Sitting and mobile using & 0 & 0 & 1 & 0 & 1 & 0 & 0 & 0 & 2 & 0 & 2 \\
\hline Sitting and reading & 1 & 0 & 1 & 0 & 0 & 0 & 0 & 0 & 2 & 0 & 2 \\
\hline Sitting and playing & 0 & 0 & 0 & 1 & 0 & 0 & 0 & 0 & 0 & 1 & 1 \\
\hline Total number of seated activities & 13 & 6 & 47 & 66 & 27 & 64 & 1 & 0 & 87 & 136 & 224 \\
\hline \multicolumn{12}{|l|}{ Great South Road } \\
\hline Sitting/people watching & 20 & 3 & 88 & 67 & 27 & 9 & 1 & 0 & 136 & 79 & 215 \\
\hline Sitting and talking & 0 & 12 & 0 & 133 & 0 & 17 & 0 & 2 & 0 & 164 & 164 \\
\hline Sitting, talking and eating & 0 & 3 & 0 & 33 & 0 & 4 & 0 & 0 & 0 & 40 & 40 \\
\hline Sitting, talking and smoking & 0 & 0 & 0 & 0 & 0 & 9 & 0 & 1 & 0 & 10 & 10 \\
\hline Sitting and eating & 5 & 0 & 13 & 35 & 5 & 4 & 0 & 0 & 23 & 39 & 62 \\
\hline Sitting and smoking & 1 & 2 & 13 & 12 & 0 & 0 & 0 & 0 & 14 & 16 & 30 \\
\hline Sitting and mobile using & 0 & 0 & 10 & 5 & 3 & 0 & 0 & 0 & 13 & 3 & 16 \\
\hline Sitting and reading/writing & 1 & 0 & 1 & 0 & 1 & 1 & 0 & 0 & 3 & 1 & 4 \\
\hline Total number of sitting activities & 27 & 20 & 125 & 285 & 36 & 44 & 1 & 3 & 189 & 252 & 541 \\
\hline
\end{tabular}

$E$ European, $M P$ Maori/Pacific Islander, $A$ Asian, $O$ other ( $I$ individual activities and $G$ group activities)

Table 3 Seated activity among people with different cultural background on private seating, Riddiford Street

\begin{tabular}{lrrrllllllll}
\hline Type of business & \multicolumn{1}{l}{ Cultural background } \\
\cline { 2 - 11 } & E/I & E/G & PM/I & PM/G & A/I & A/G & O/I & O/G & Total/I & Total/G & Total \\
\hline Cafés & $\mathbf{4 2}$ & $\mathbf{1 0 6}$ & 5 & 3 & 2 & 0 & 1 & 0 & 50 & 109 & 159 \\
Bakeries & 14 & 14 & 8 & 5 & 3 & 0 & 2 & 2 & 27 & 21 & 48 \\
Bars & 1 & 5 & 2 & 0 & 0 & 0 & 0 & 0 & 3 & 5 & 8 \\
Total & 57 & 125 & 15 & 8 & 5 & 0 & 3 & 2 & 80 & 135 & 215 \\
\hline
\end{tabular}

Europeans were most often seen to socialise on café seating which is indicated in bold relaxing and do not like to be completely separated from the city (Gehl 1987; Mehta 2006; Whyte 1980). People watching is an important activity on streets and good vantage points were valued among the participants of this study. Factors such as the edge effect, prospect and refuge, and environmental comfort characteristics were of secondary importance compared to people's attraction to business and other land-use activities. 


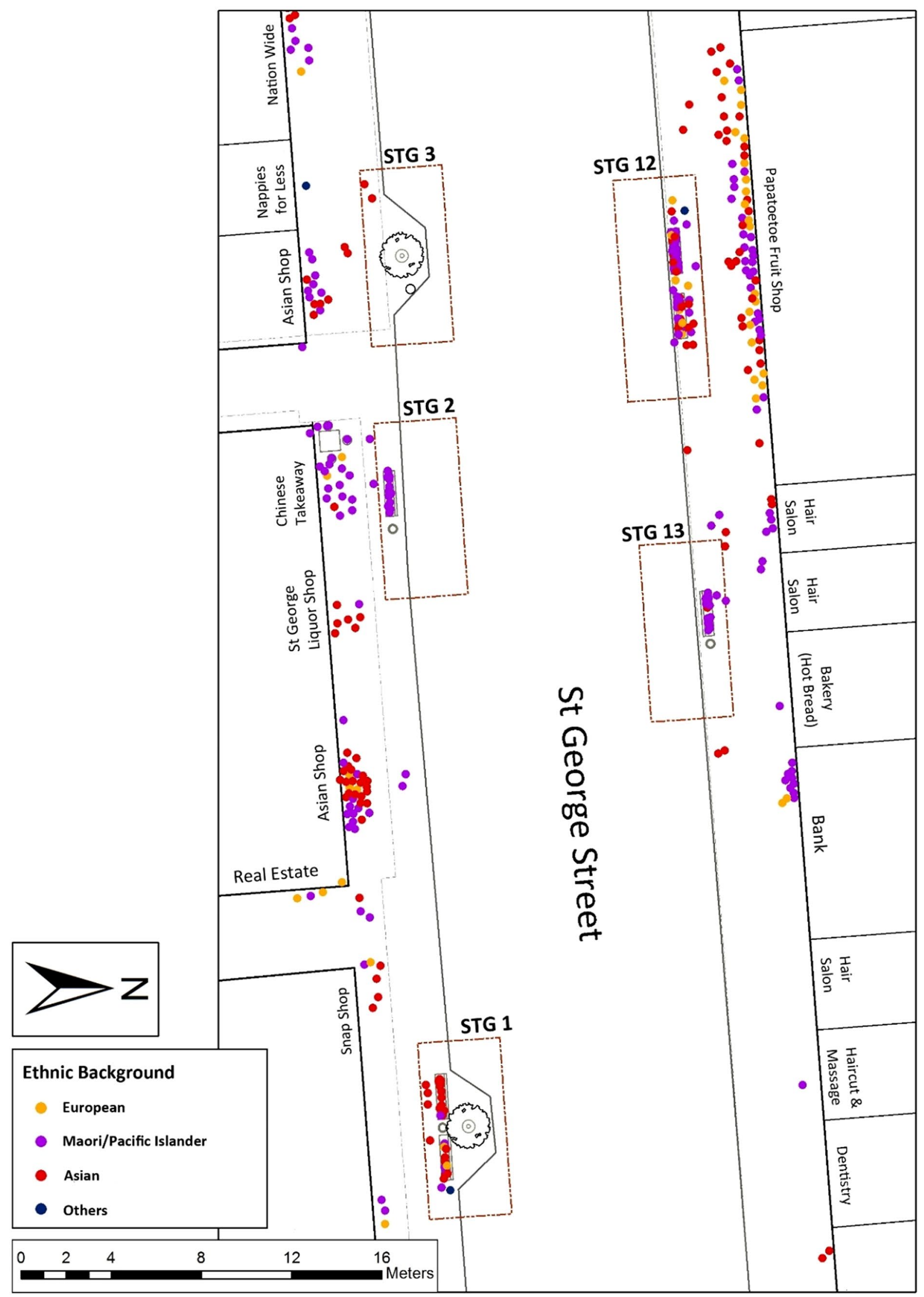

Fig. 7 An example, from St George Street in Otahuhu, of how people's behaviours were recorded in the study 
People preferred to sit on benches located in zone "A", where they could have their backs protected and have a broader view than benches located elsewhere (Fig. 8). On the other hand, benches in zone " $\mathrm{C}$ " along active sections of the streets were used more frequently than those located in Zone "A" with lower pedestrian flows (spaces RID10, RID17, and RID18 on Table 4). Similarly, seating located in areas judged to have higher amenity levels (environmental qualities such as landscaping and shade) but removed from pedestrian flows were less often occupied. Bosselmann (2008, p. 247), noted that "the desire to gather where other people are, or at a close distance of them to be able to observe the optional activities that predictably take place, is almost universally common". It could be concluded that the location of benches follows the same rule in streets in multi-cultural contexts. Therefore, locating benches in active sections of streets supported by businesses is the most important factor ensuring their use for social activities. There was not a clear correlation between landscaping and number of stationary

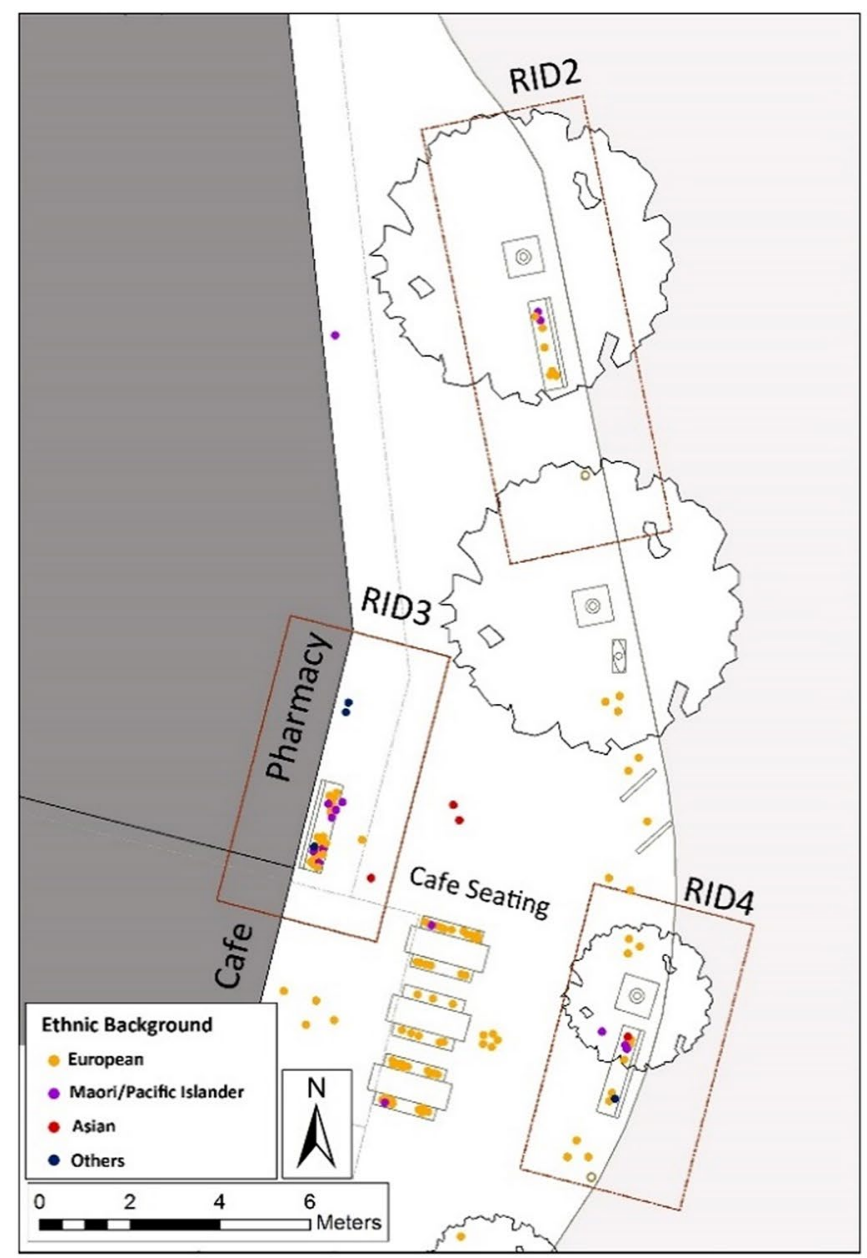

activities, however, the attractiveness of planting was often mentioned by people in the interviews. Other factors that arose frequently in the interviews included the number of seats provided, their associated characteristics, distance from road and pedestrian traffic, and shop front management.

There were differences in the social structure and group size of the different cultures whose behaviours were mapped along the three streets. Activities by Europeans involved small to medium sized groups. Māori/Pacific Islander groups comprised smaller and larger numbers of people in groups (Table 5). It is unfortunate that neighbourhood streets are somewhat blind to ethnic culture. For instance, Pacific Islanders frequented public benches in Great South Road in numbers that could be anticipated by the demographic profile of the neighbourhood. However, the number and arrangement of seating did not accommodate group sizes preferred by Pacific Islanders, leading some members to have to stand or squeeze uncomfortably together on benches. Even when adequate numbers

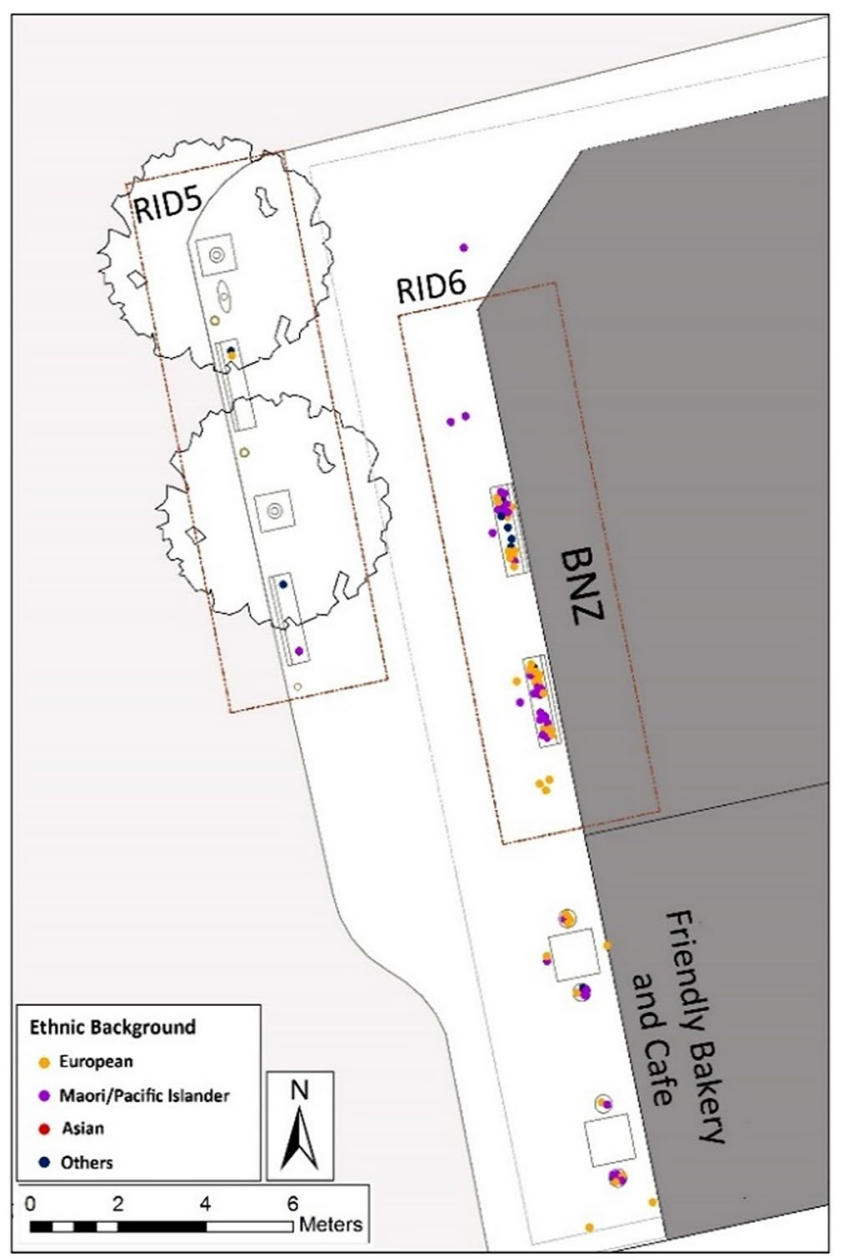

Fig. 8 The edge effect; observations show that in spaces within similar locations and characteristics, seating located in open parts of the space got less frequently occupied compared to the edges (Look at Spaces RID5 and RID6 and RID3 and RID4) 


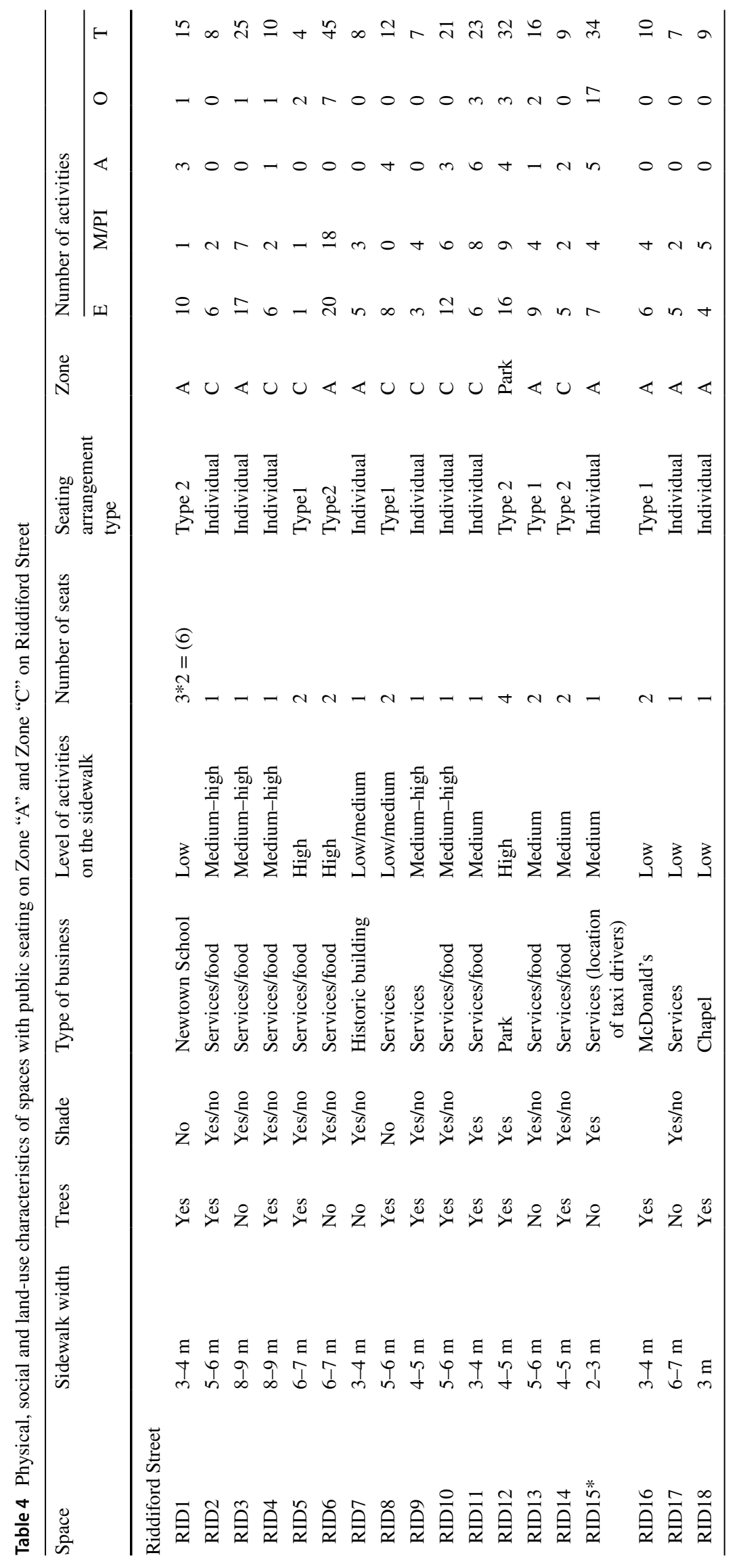

张 
Table 5 Group sizes among different ethnic groups in the studied areas

\begin{tabular}{llrrrrrrrrrr}
\hline Street & Ethnic group & Group sizes & & & & & & & \\
\cline { 2 - 11 } & & Individual & 2 & 3 & 4 & 5 & 6 & 7 & 8 & 9 \\
\hline \multirow{2}{*}{ Riddiford Street } & Europeans & 317 & 139 & 43 & 10 & 3 & - & 1 & - & - \\
& Maori/Pacific Islanders & 110 & 43 & 13 & 5 & 3 & - & - & - & - \\
& Asians & 48 & 31 & 4 & 6 & - & - & - & - & - \\
& Others & 30 & 19 & 2 & - & 1 & - & - & - & - \\
& Total & 505 & 232 & 62 & 21 & 7 & - & 1 & - & - \\
& Europeans & 68 & 13 & 3 & - & - & - & - & - & - \\
& Maori/ Pacific Islanders & 157 & 80 & 17 & 3 & 1 & 4 & - & - & - \\
& Asians & 101 & 63 & 16 & 6 & 1 & - & - & - & - \\
& Others & 4 & 2 & - & - & 1 & - & - & - & - \\
& Total & 330 & 158 & 36 & 9 & 3 & 4 & - & - & - \\
Grearge Street South Road & Europeans & 55 & 22 & 5 & 1 & - & - & - & - & - \\
& Maori/Pacific Islanders & 475 & 289 & 121 & 51 & 20 & 5 & 3 & 1 & 3 \\
& Asians & 204 & 114 & 36 & 13 & 2 & 1 & - & 1 & - \\
& Others & 5 & 3 & 1 & - & - & - & - & - & - \\
& Total & 739 & 428 & 163 & 65 & 22 & 6 & 3 & 2 & 3 \\
\hline
\end{tabular}

A considerable number of activities involves groups of four persons and more in Great South Road, Otahuhu of seats were provided, they were located far away from each other causing the group to be divided. Interviews suggested the importance of tables for the leisure and social activities of diverse groups (Fig. 9).

The ethnographic fieldwork looked at activity along three specific streets, the physical characteristics of which is unique. While the study helped reveal people's seating preferences it did not enable preferences for design characteristics to be understood. Accordingly, a second stage that could provide correlational data was developed.

\section{Stage two: visual preference survey}

Following up on the initial findings, a Visual Preference Survey (VPS) invited people to rank their preferences for different seating conditions and seating arrangements. The framework for this questionnaire referenced observations and interviews in the first stage as well as the literature. Response stimuli were photographs of computer-simulated images, illustrating potential footpath spaces. See Fig. 10. Each simulation set comprised between two and five images, which were displayed vertically on one side of a web page.

A range of different seating arrangements were examined in the survey, and the images varied from one another

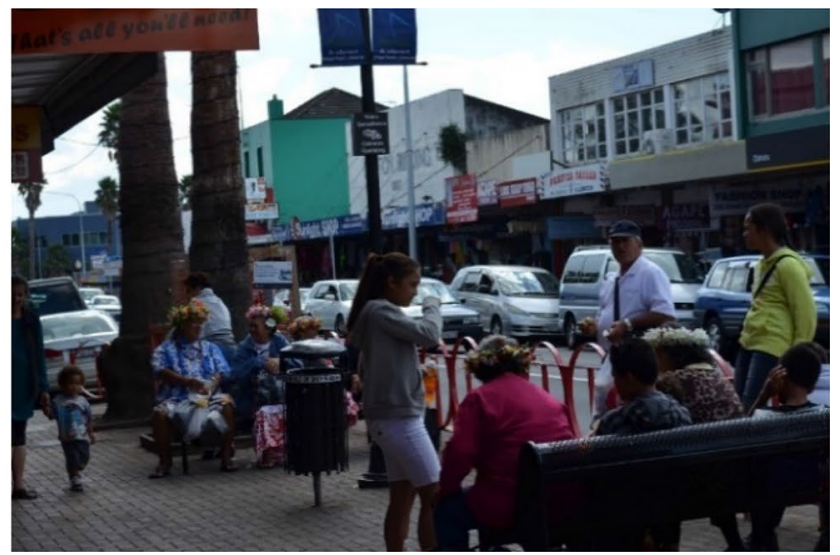

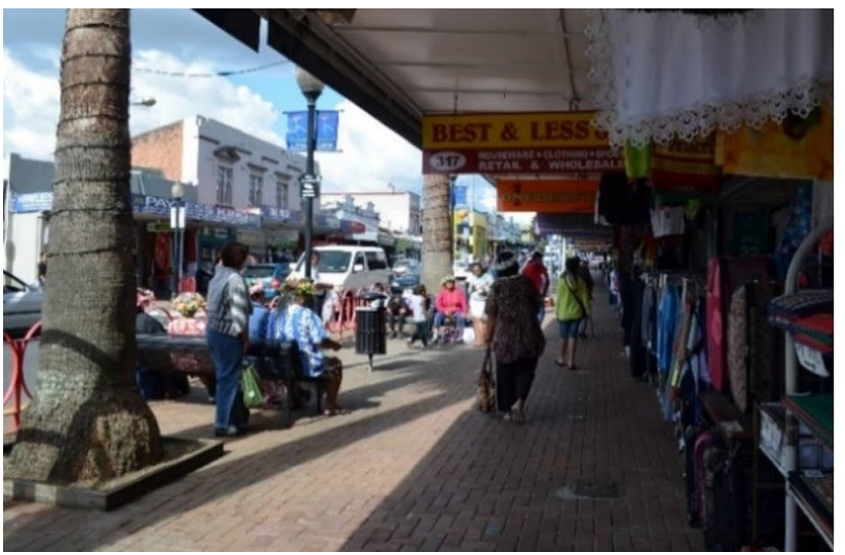

Fig. 9 Great South Road, Otahuhu. Benches are located too far away from each other to be conveniently used by the members of one large group. Source: First author 2013 

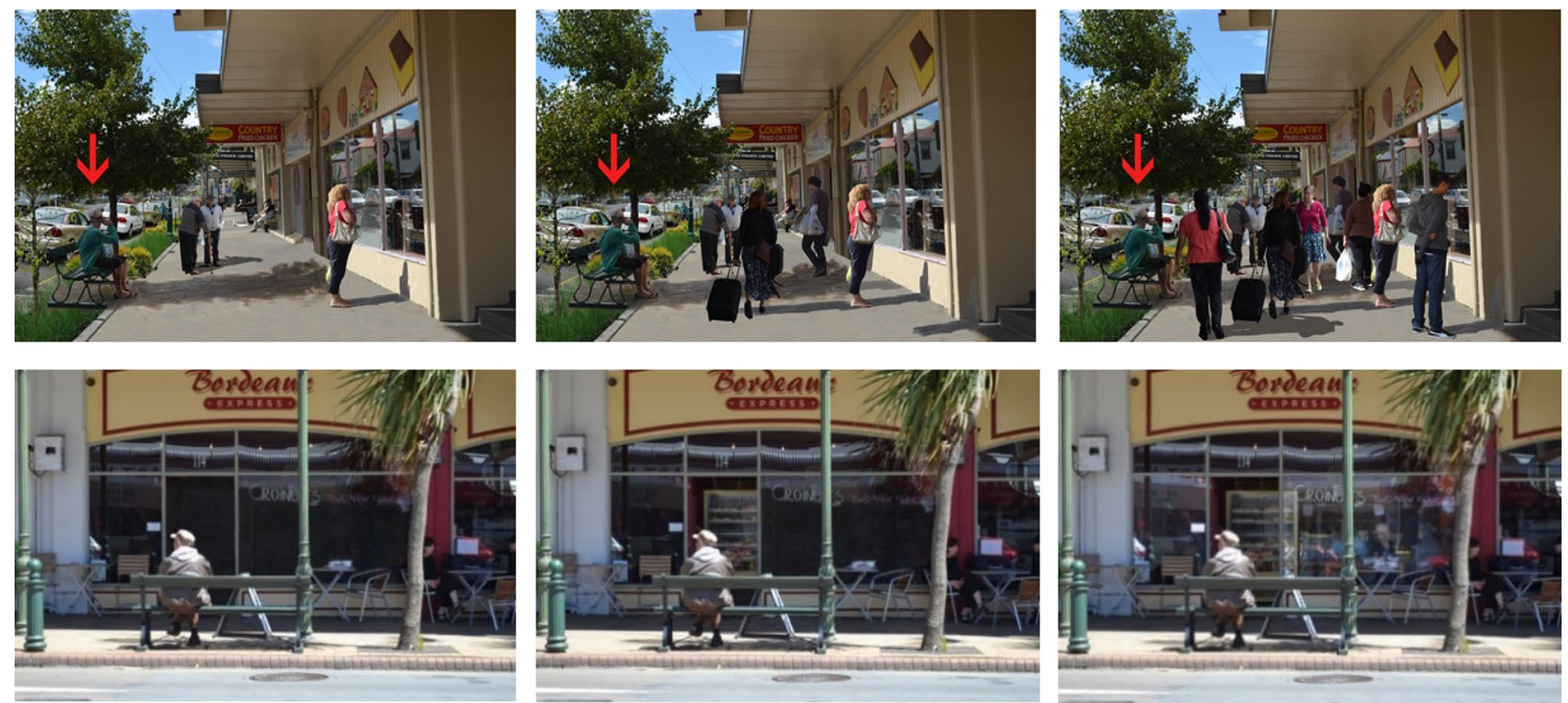

Fig. 10 Top: Participants were asked to rate their preference for sitting on the benches with three density levels. Bottom: participants were asked to rate their preference for sitting on the bench facing a shop with three levels of visual permeability. Left image: shop with opaque and dark windows, middle image: shop with partly opaque and partly visually permeable windows and right: shop with all windows visually permeable by shop frontage, seating location, seating orientation and type of landscape edging the footpath. Planting and landscape treatment had been frequently raised in the interviews. In addition, many people noted that they preferred seating that was set back from a busy road. This led the researchers to investigate whether landscaping could serve as a buffer between seating and traffic. Three landscape types were specified. Landscape type L1: no planting along the edge. Landscape type L2: low planting along the edge, enabling views out over the road and traffic. Landscape type L3: tall planting along the edge that acts as a visual barrier to the road and traffic. Shop frontage management is also an important issue for seating located in zone " $\mathrm{C}$ " (refer to Fig. 6). In order to make a better comparison between different seating types, three shop frontage types that were most commonly seen in the case study streets were represented. One pertained to businesses that kept their goods inside the shop (SF1). The second shopfront contrasted with this condition by allowing their goods to spread out onto the sidewalks (SF2). Finally, cafés with sidewalk seating were considered as the third type of frontage (SF3).

In order to understand what types of seating are appropriate for sidewalks, the VPS addressed a range of seating arrangements. The purpose was to measure how supportive each group felt about a variety of seating arrangements in sidewalk spaces while visiting by themselves or with their ethnicity centred group. Furniture was displayed in 'sociopetal 'or 'socio-fugal' arrangements in a number of different settings. Finally, survey participants were asked to state their preferences for different pedestrian density levels and shopfront permeability levels while seated and facing onto the sidewalk.

Respondents rated each scene on a seven-step scale, from 'extremely disliked' to 'extremely liked'. The survey enabled any effects created by the social environment to be minimised and extended the study to a larger number of people. A total of 181 people participated in the survey, with 78 (43\%) being male and 103 (57\%) being female. The sample included 41 Europeans (22.6\%), 32 Māori (17.6\%), 34 Pacific Islanders (18.8\%), 46 Asians (25.4\%) and 28 (15.6\%) from other ethnicities (Fig. 11).

As responses to the VPS were numerical, they were easily analysed by generalized estimating equations, repeated measures analysis of variance, and one-way ANOVA. The mean response was used to measure preference for various seating conditions and arrangements and was used to compare responses from each ethnic group.

\section{User preferences}

The survey did not reveal any differences in preference for seating conditions between different ethnic groups $(p=.779)$, but it did suggest that the location and orientation of benches and how they relate to other characteristics such as landscaping, shop frontages and population density $(p=0.1)$ does influence choice (Tables 6 and 7).

While benches with fewer activities around them were occupied less frequently, survey respondents preferred 

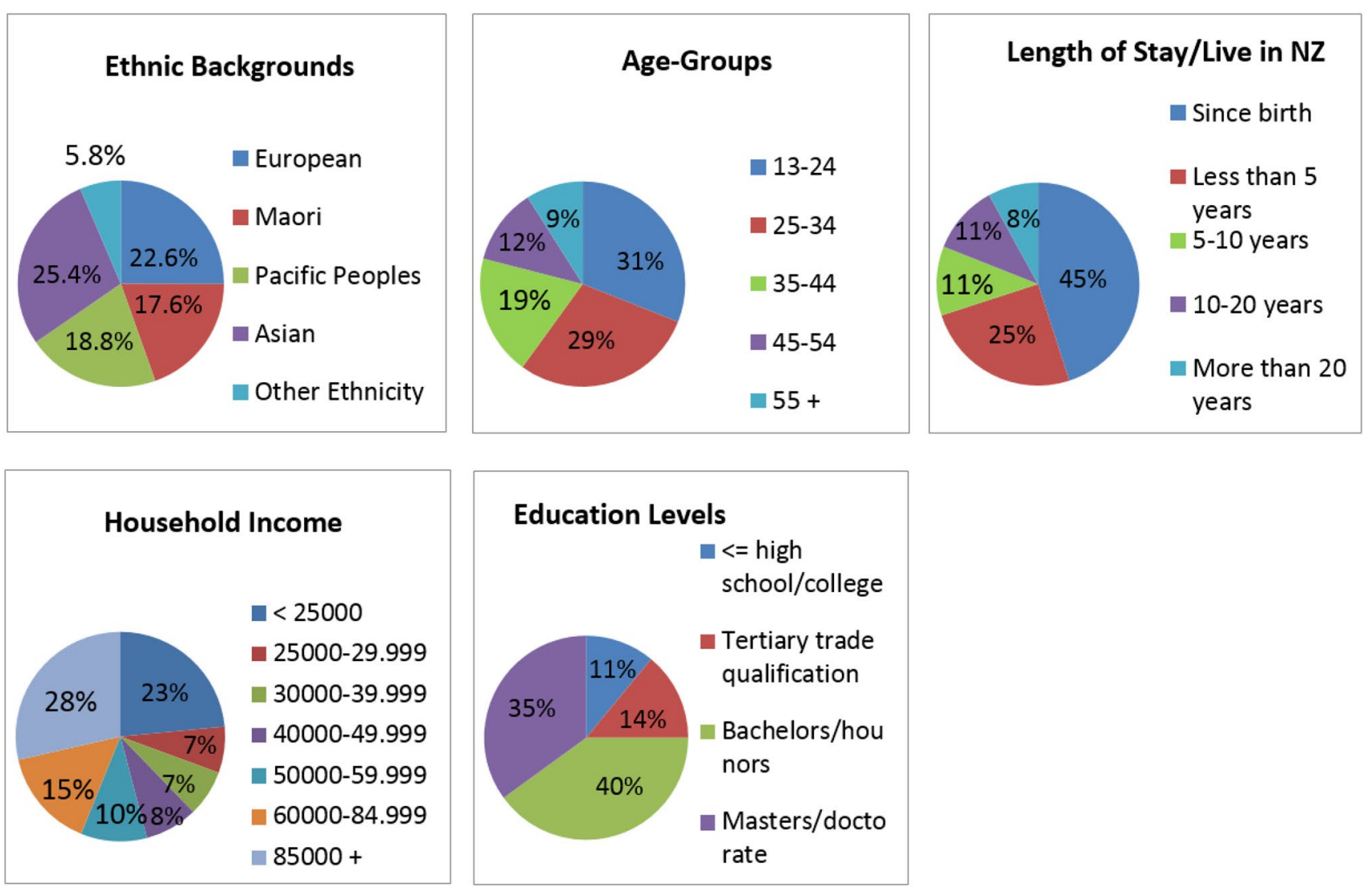

Fig. 11 Demographic characteristics of the participants

Table 6 Tests of model effects show different types of shop frontage, bench, landscape + interactions all have a statistically significant $p$ value

\begin{tabular}{lrcc}
\hline & Wald $\chi^{2}$ & df & $p$ value \\
\hline (Intercept) & 2188.344 & 1 & .000 \\
Shop & 29.777 & 2 & .000 \\
Bench & 187.010 & 4 & .000 \\
Landscaping & 89.208 & 2 & .000 \\
Shop*Bench & 23.507 & 2 & .000 \\
Shop*Landscaping & 27.533 & 4 & .000 \\
Bench*Landscaping & 90.911 & 8 & .000 \\
Shop*Bench*Landscaping & 20.706 & 4 & .000 \\
\hline
\end{tabular}

seating spaces removed from the crowd. Similarly, lower densities of people were preferred in the VPS to simulations exhibiting higher levels (Fig. 12). These results could be seen to fit well with the strong and ongoing preferences of New Zealanders to live in suburban settings. Reflecting further, these results can also be read as confirmation of earlier studies on personal space preferences. At low densities, the effect on people's sense of personal space seems tolerable. However, as densities increase, benefits of sitting close to the
Table 7 Tests of model effects show different bench type and level of density + interactions all have a statistically significant $p$ value

\begin{tabular}{lrlc}
\hline Source & \multicolumn{2}{l}{ Type III } & \\
\cline { 2 - 4 } & Wald $\chi^{2}$ & df & $p$ value \\
\hline (Intercept) & 1377.771 & 1 & .000 \\
Bench & 43.903 & 1 & .000 \\
Density & 134.007 & 2 & .000 \\
Bench*Density & 20.608 & 2 & .000 \\
Bench*Density*Ethnic & 20.185 & 8 & .010 \\
$\quad$ group & & & \\
\hline
\end{tabular}

action are outweighed by personal space concerns. It would, therefore, seem appropriate to plan for low people densities around seating areas, as each of the cultures we studied preferred to sit "within view of the action, but out of the way of the flow of pedestrian traffic" (PPS 2008a). This could be achieved by increasing the width of the sidewalk in seating areas with medium or high-density levels.

While people would like to have their backs protected by buildings lining the street, they also prefer to have a pleasant outlook over the wider setting. Landscaping treatment along the street edge (zone "C") was very important. Planning for 


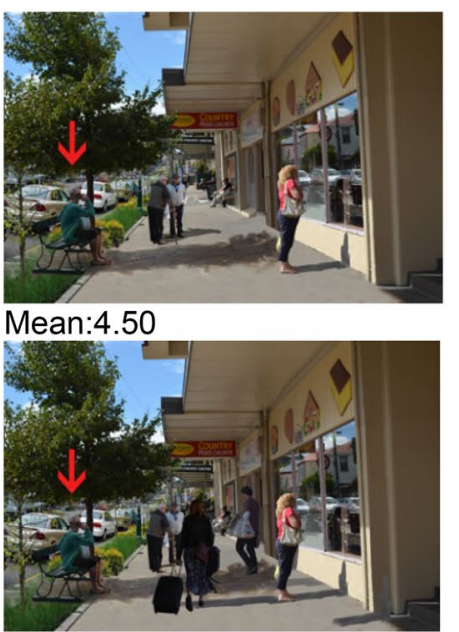

Mean:3.77

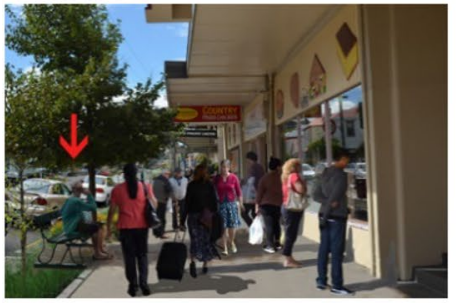

Mean:2.99
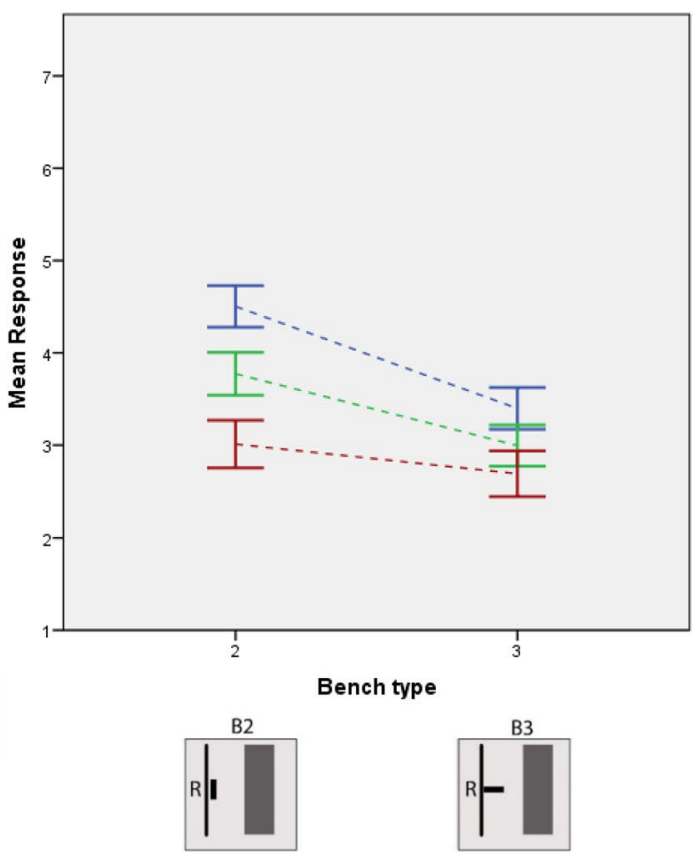

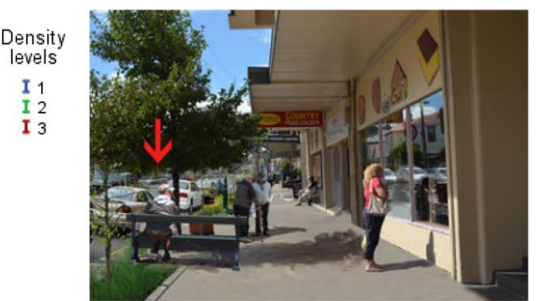

Mean:3.40

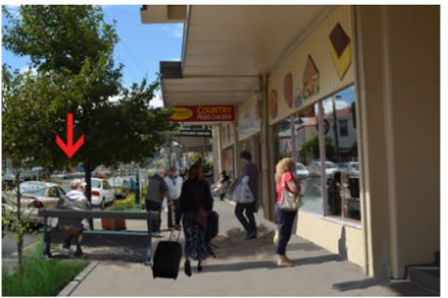

Mean:3.01

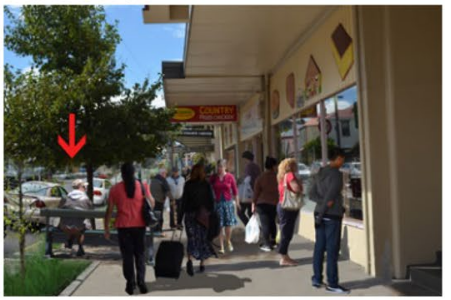

Mean:2.69

Fig. 12 Mean and 95\% confidence interval of preference for different type of density while seated on various bench types

low planting along the kerbline would increase the chance that users would have a broader outlook. This in turn could make the seating more inviting to members of different ethnic groups. On the other hand, people gave very low preference ratings to one bench facing another bench in the same sidewalk (Fig. 13).

The value of the buffering that planting provides when seating is located in zone "C" was also confirmed. Planting height is not a factor, however, when the bench has its back toward traffic. A seating bench placed perpendicular to the sidewalk received the lowest preference rating of all seating conditions presented to survey respondents. While planting was of lower importance while seated perpendicular to the sidewalk than in other seating conditions, there was a preference for some form of landscaping over having none. Thus, when planning for seating perpendicular to the footpath it is essential to provide some form of landscaping along zone "C" to enhance preferences and use.

In general, participants favoured the organised shop frontage and café frontage compared to the shop frontage spreading onto the sidewalk relative to parallel or perpendicular seating conditions (Fig. 14). It appears that people would not like to sit where the bench faces the sidewalk and a café with outdoor seating and activities as much as they would like to sit in front of an organised shop front without outdoor activities. This finding conflicts with observations where seating locations and activities show strong associations. One explanation could be that people like to observe dynamic activities while seated but feel less comfortable to face sedentary activities directly. This also coincides with the low mean preference of participants for sitting on benches in front of each other on two sides of the sidewalk. Urban designers may wish to recognise personal space preferences and the concept of proxemics (Hall 1966) when locating benches near business activities.

The configurations of shop fronts were less important to respondents when they were invited to consider seating placed perpendicular to the sidewalk direction. While there were also slight differences in which shopfront type respondents preferred to sit near while seated perpendicular or parallel to the sidewalk, all respondents gave the condition where shops extended their merchandise out into the public space their lowest preference score. It is, therefore, advisable that seats not be located in close proximity to such shopfronts.

In addition to preferring the 'organised' shop frontage type, all four ethnic groups would prefer to sit in front of premises with higher levels of visual permeability (Fig. 15). This corresponds with observations by Carmona et al. (2010) that people like to engage with activities taking place inside businesses. People like to use and sit in spaces where they can see activities. Thus, it would be preferable to locate seating in front of premises with higher levels of 

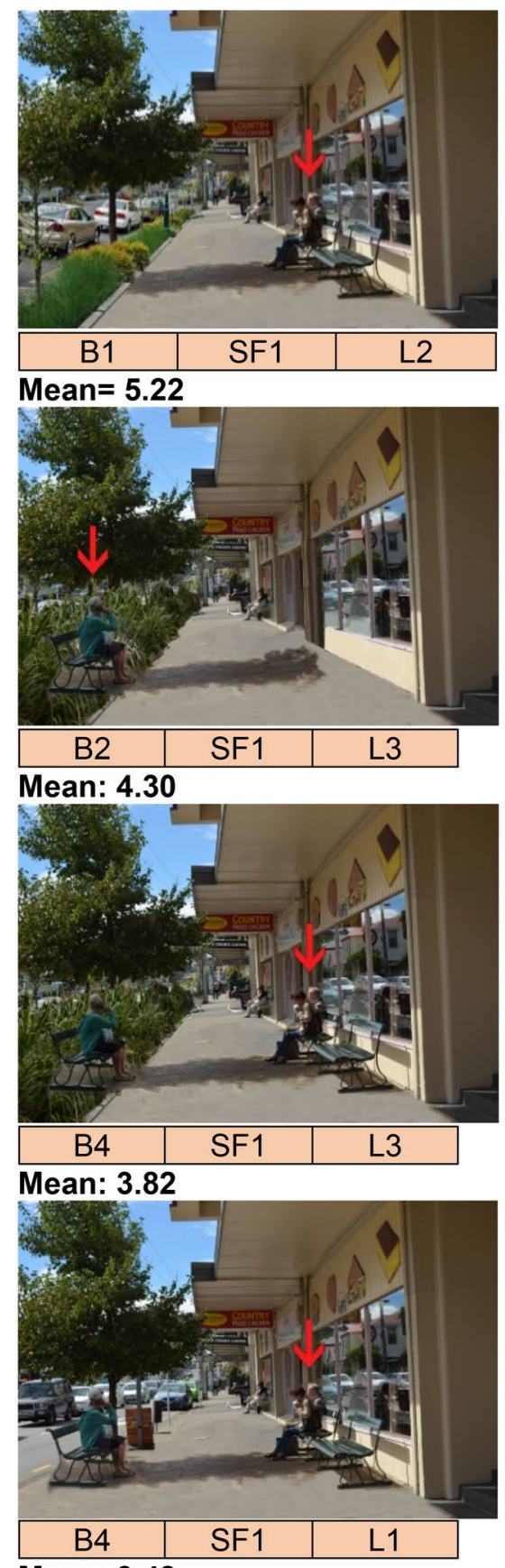

\section{Mean: 3.48}

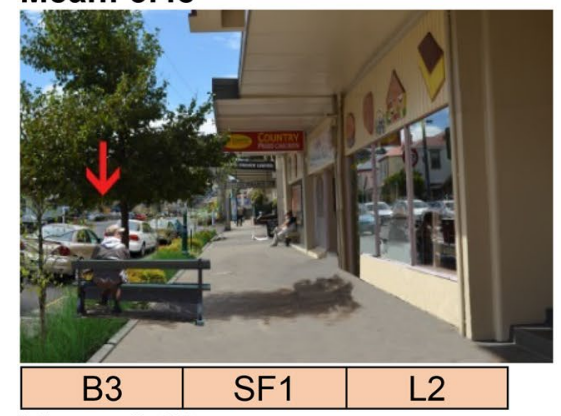

Mean: 3.02
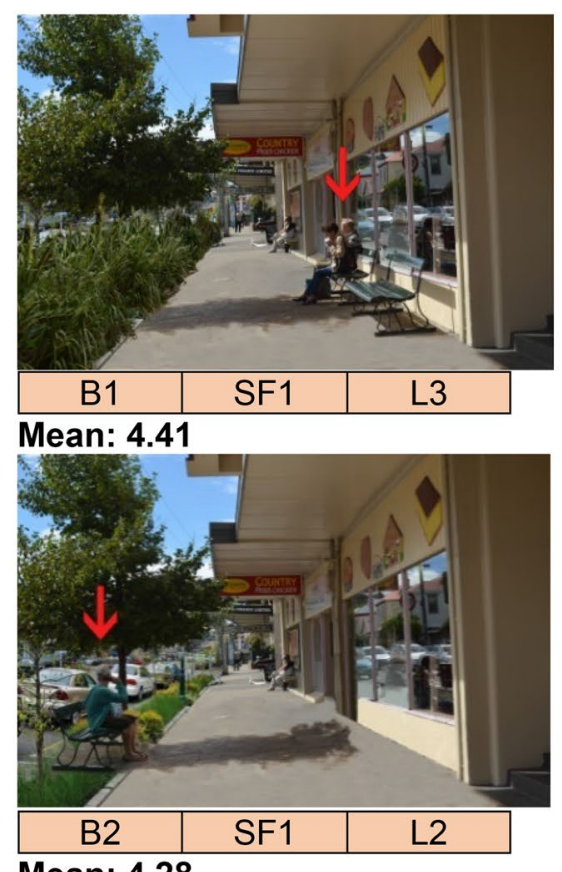

\section{Mean: 4.28}

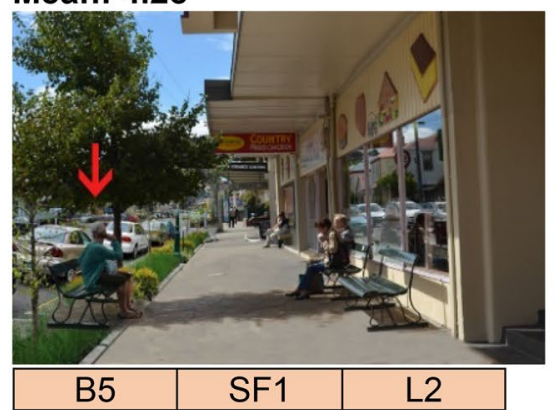

\section{Mean: 3.52}

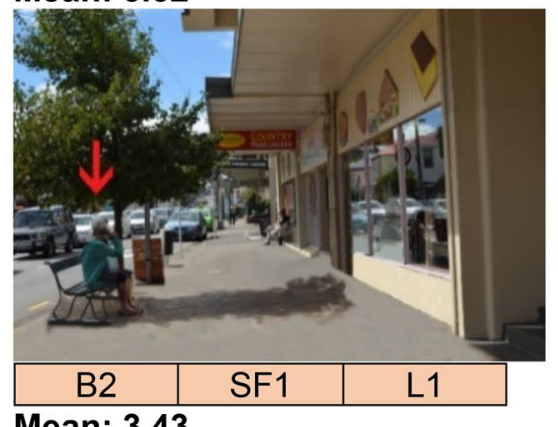

\section{Mean: 3.43}

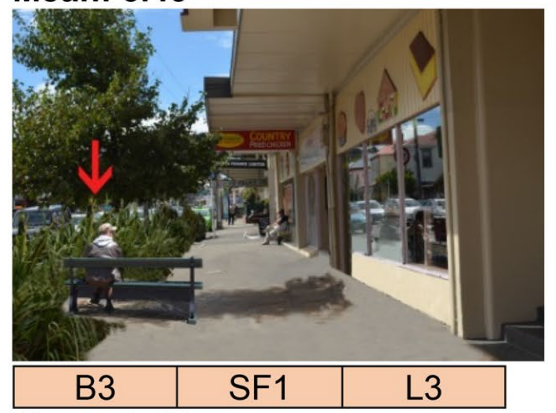

Mean: 3.02

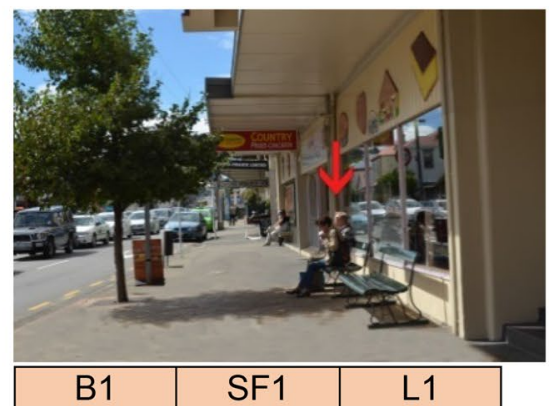

\section{Mean: 4.31}

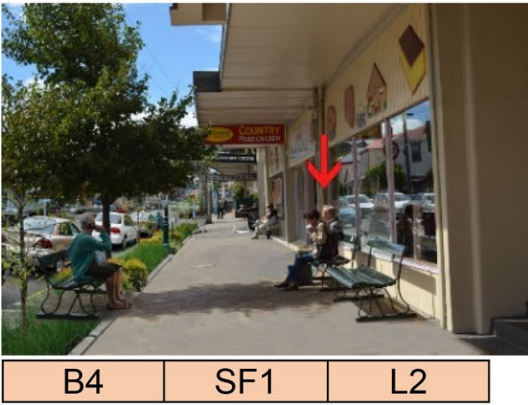

\section{Mean: 3.92}

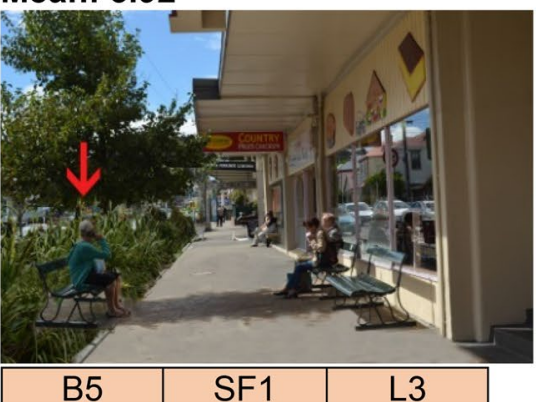

\section{Mean: 3.48}

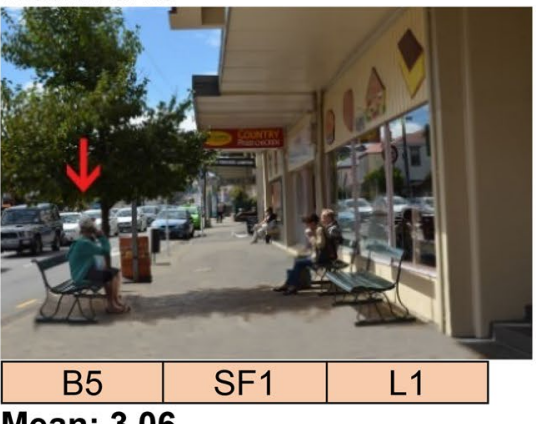

Mean: 3.06

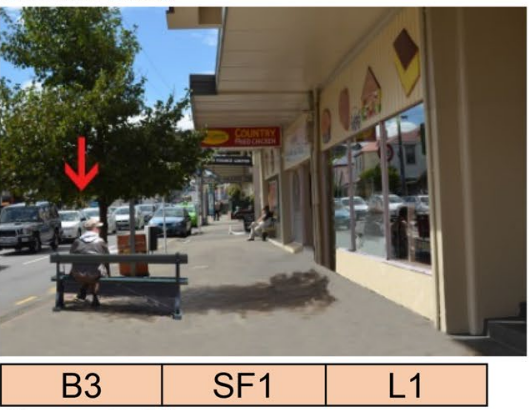

Mean: 2.81

Fig. 13 Preferred seating situations in a descending order from upper left to bottom right 

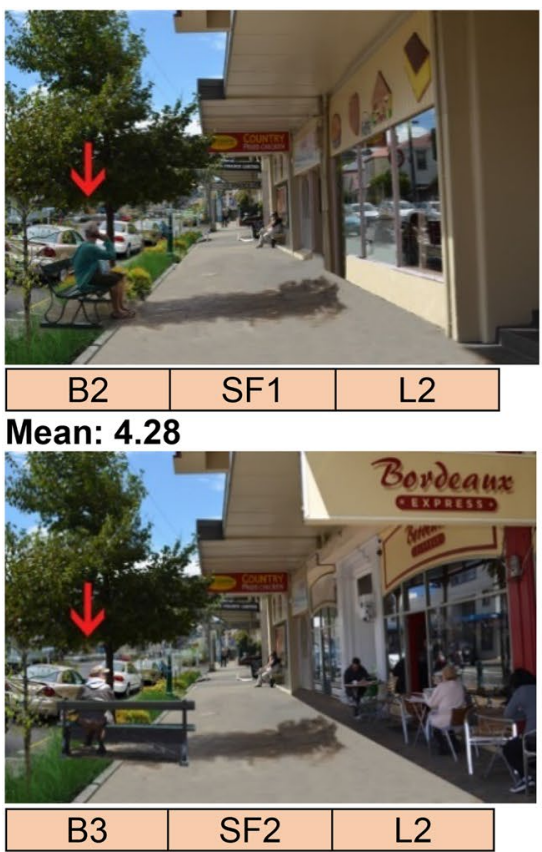

Mean: $\mathbf{3 . 1 2}$
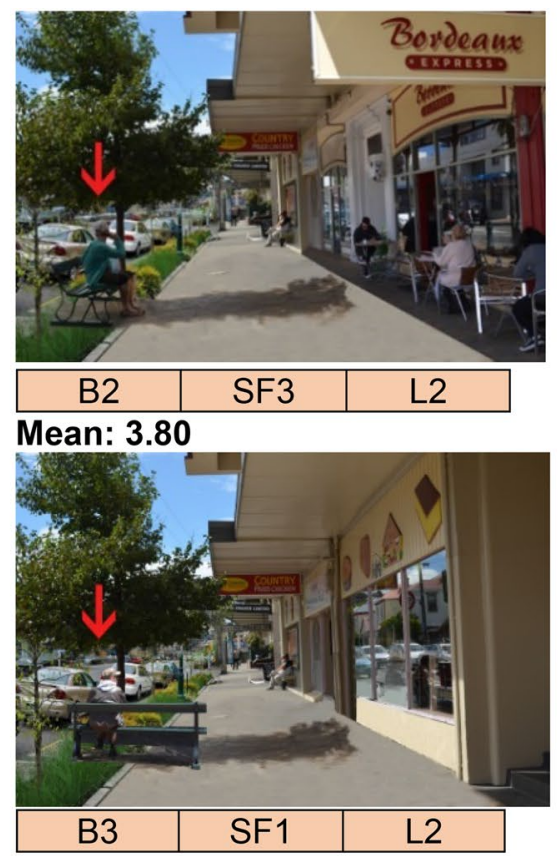

Mean: 3.02

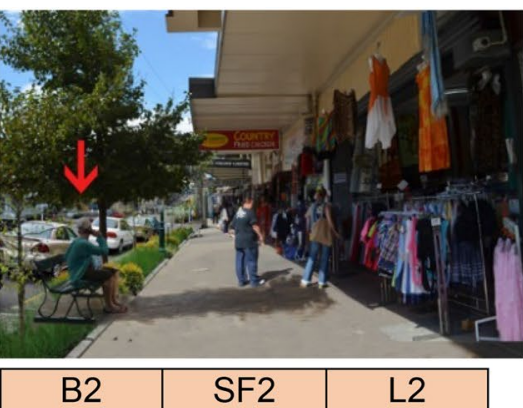

Mean: 3.48

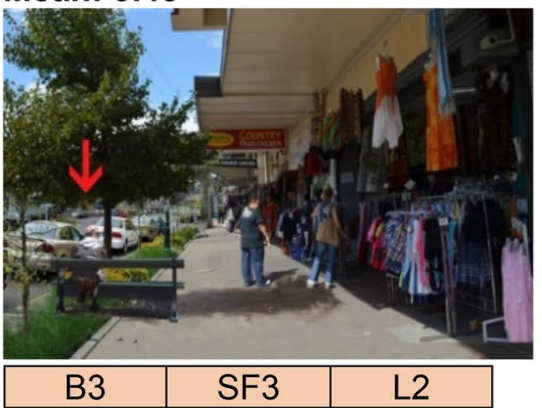

Mean: 2.81

Fig. 14 Preferred seating situations over different shop frontage types

visual permeability where there is a possibility of facing activities on streets in multi-cultural societies.

A range of seating arrangements were addressed in the VPS. As expected, socio-fugal arrangements were preferred more for individual activities and socio-petal arrangements were favoured for social activities. However, some sociopetal seating types, such as those around a table, also found preference for individual activities among respondents. Socio-fugal seating types were also favoured for social activities; These situations were most popular among Europeans and Asians, as these respondents generally came to the street in smaller groups. It seems important that socio-fugal, linear arrangements of seating are not placed next together. Such arrangements do not encourage social activities as it makes face-to-face interactions difficult. In addition, it discourages individuals from using them. A considerable number of Pacific Islanders and Māori come to the street in larger groups, and they had a higher preference for bigger sociopetal seating arrangement types. Thus, a number of larger, socio-petal seating arrangements in areas with higher numbers of Māori and Pacific Islanders would seem appropriate.

The study found an overall preference for 90-deg orientation over face-to-face orientation of benches for social activities. While Europeans preferred to sit on benches side by side rather than in front of each other, there were no such differences among Māori respondents (Fig. 16). It is clear that furniture arrangements could affect the quality of interactions among different ethnic cultures. However, as the $90-$ deg orientation was preferred by a diverse range of cultures, arranging seating in this manner on sidewalks where the aim is to cater to all ethnicities would seem sensible. Selecting a 90-deg arrangement could also increase the chance of this type of arrangement to be used by individuals to sit alone, as "people tend to feel uncomfortable when they sit face-to-face with a stranger, and will twist around or sit sideways to avoid eye contact"(PPS 2008a).

The VPS confirmed the value of tables for leisure, social and individual activities of diverse groups. Tables have been neglected in public street furniture designs as they are mostly associated with commercial areas. Survey responses also suggest that seating should not be placed face-to-face unless there is a table between them (Fig. 17).

\section{Discussion}

The observations confirmed the importance of business activities in people's decisions on where to sit (Jacobs 1993; Mehta 2013). Placing preferred seating arrangements close to businesses that support social activity increases the potential that they will be used. This research found some business activities to be more relevant to social activities than others; an example of this is the attractiveness of affordable eating places for Māori and Pacific Islanders. Through the VPS we understand the seating types preferred by these ethnic groups for social activities. Placing comfortable areas to sit, located close to activity supporting businesses along 

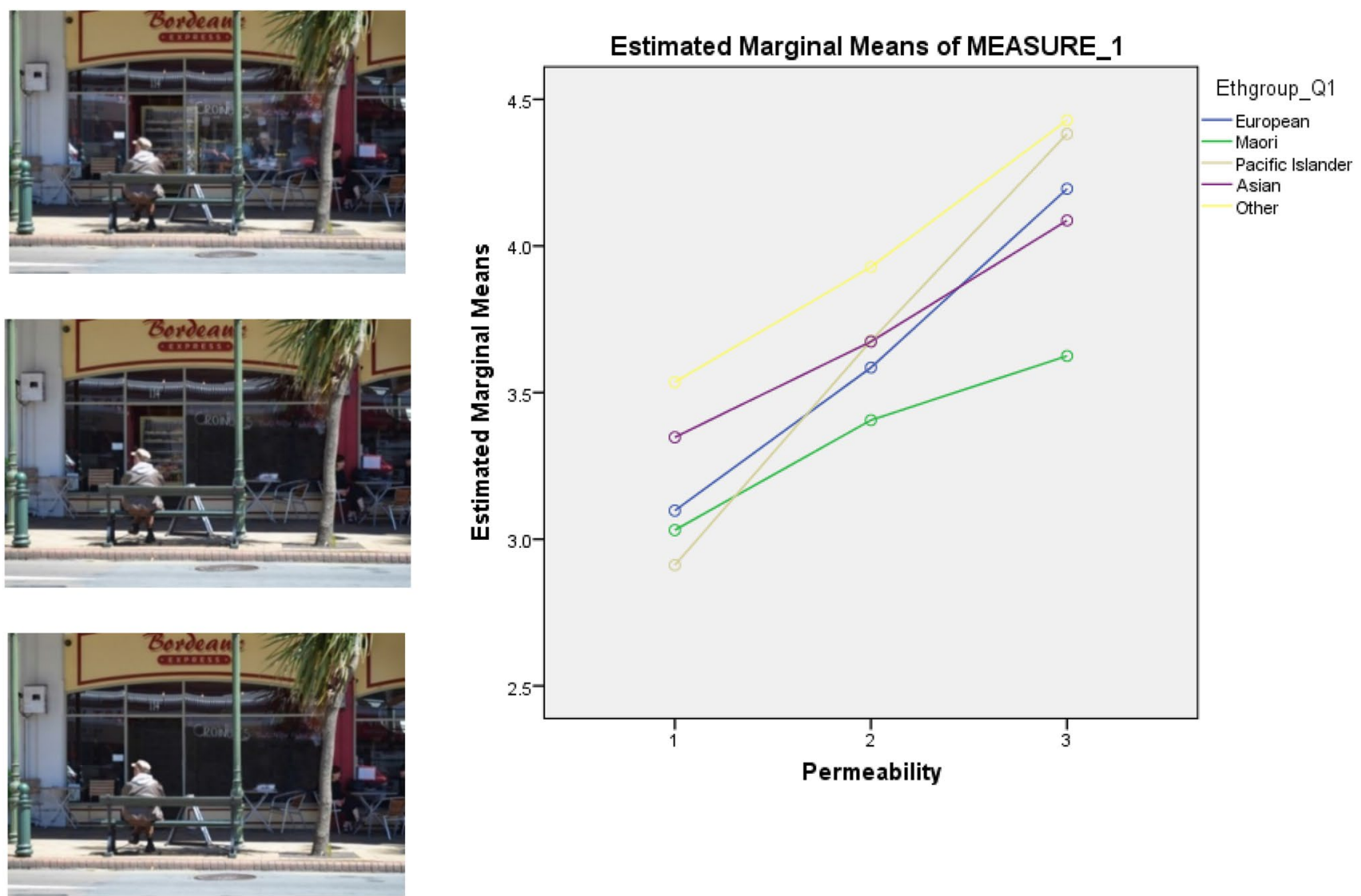

Fig. 15 Repeated Measures Analysis was utilized to measure difference among three levels of visual permeability.1: shop with opaque and dark windows, 2: shop with partly opaque and partly visually permeable windows and 3: shop with all windows visually permeable (By the Wilk's Lambda test, there was a significant difference

sidewalks, could increase the length of time people from different cultural backgrounds spend on sidewalks.

Confirming the earlier work of Parham $(1992,2012)$, this project has found that the relationship between design and food-oriented social practices contributes to convivial and vibrant urban places. Seating arrangements, including tables, placed in close proximity to bakeries and takeaway food outlets was seen to increase stationary and social activities along sidewalks. Therefore, placing larger seating arrangements adjacent to affordable eating premises such as Asian or Pacific Island takeaways could create circumstances that would support the social activities of these groups.

Many of the preferred seating arrangements have large footprints, particularly where they include landscaping treatments. Few locations along New Zealand streets are wide enough for these types of arrangements. More generous sidewalks could provide opportunities for cafés and other commercial businesses to expand their interior space onto the sidewalks than narrow sidewalks. This will in turn increase the potential for liveliness and sociability along the street. in mean preference for sitting in front of shops with three levels of visual permeability (Wilk's, $F(2,175)=23.803, p=.000$ ). However, there was no difference in this preference by ethnic groups (Wilk's, $F(8,350)=.712, p=.681))$

Some design variables related to seating on sidewalks can be confidently applied as they are universally liked; for example, landscape buffers could be added behind or in front of seating, and sidewalk widths could be increased by narrowing spaces designated for vehicular traffic and car parks. Unfortunately, relationships between seating and business activities are not entirely straightforward as businesses are constantly changing. This presents a real challenge to public space managers wishing to foster synergies. Committing a socio-petal seating arrangement with a large footprint close to a takeaway food establishment could see its potential as a social space dwindle with changing business profiles. Similarly, businesses could design and manage their frontages in ways that conflict with people's social or lingering needs. One suggestion here is movable seating, which offers choice, comfort and flexibility in use. These have for some time been recognised as a highly desirable public space attribute (Whyte 1980). Such seating is also less expensive in comparison with fixed benches. On the down side there is also a risk 


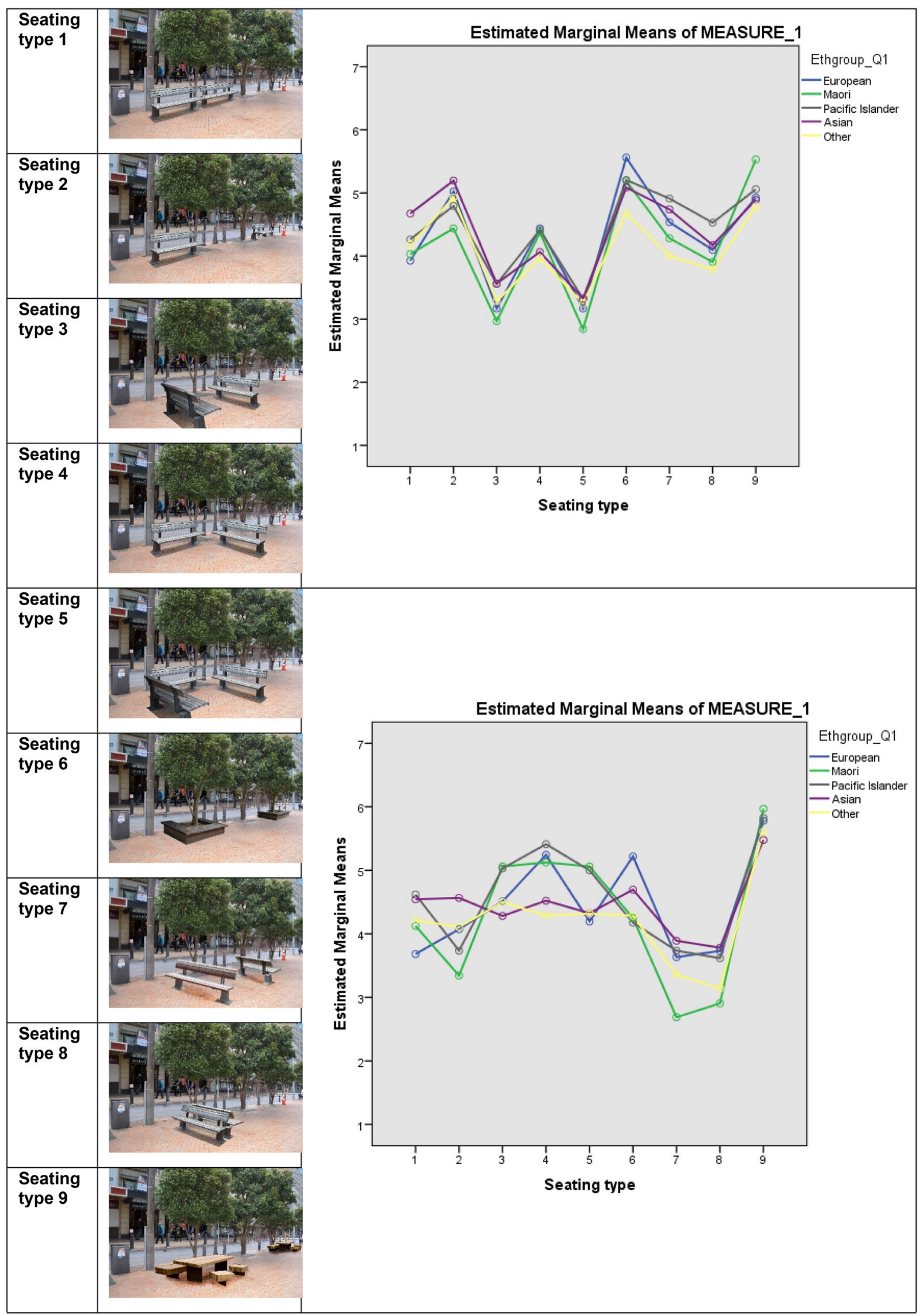

Fig. 16 Preference for different type of seating arrangements for individual (top-right) and social activities (bottom-right) by different ethnic groups 


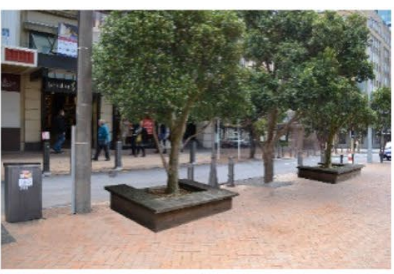

\section{Seating type 6}

Mean: $5.17 \pm 1.449$

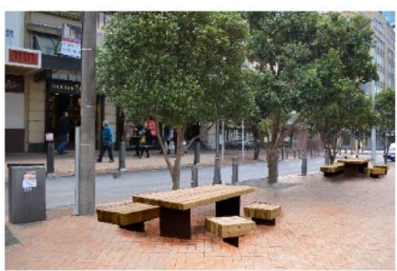

Seating type 9

Mean: 5.72 \pm 1.415

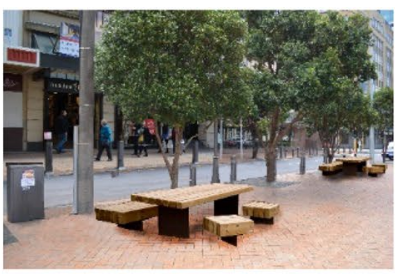

Seating type 9

Mean: $5.03 \pm 1.569$

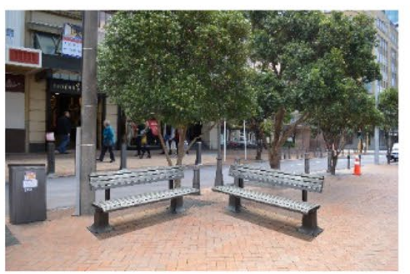

Seating type 4

Mean:4.92 \pm 1.607

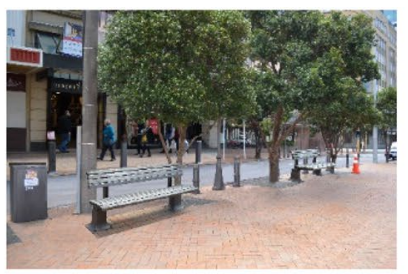

Seating type 2

Mean: 4.91士1.475

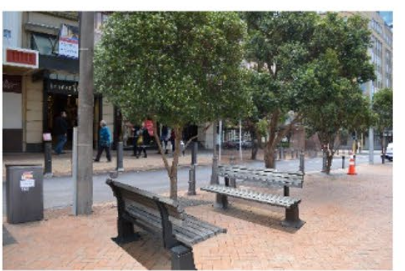

Seating type 3

Mean: $4.65 \pm 1.625$

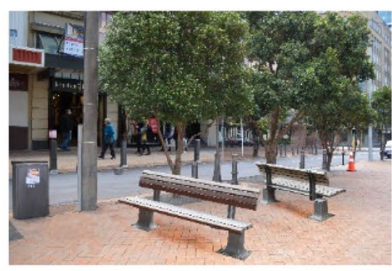

Seating type7

Mean: $4.53 \pm 1.594$

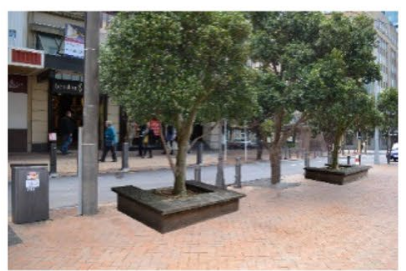

Seating type 6

Mean: $4.57 \pm 1.644$

Fig. 17 Top row: preferred types of seating arrangements for individual activities, in descending order left to right. Bottom row: preferred types of seating arrangements for social activities, in descending order left to right

that movable chairs disappear from sidewalks over time (PPS 2008a).

Another possible avenue for enhancing the attractiveness of streets to social activities could be by managing the business activities along each street block (Lesan and Gjerde 2015). Many councils have established a business development manager role to help foster new commercial activities. This role could proactively target opportunities for new businesses to establish in within close proximity to seating and other street furniture where there is evidence that co-location can lead to positive synergies. This research provides such evidence. Seating and business activities should be managed in relation to one another; addressing one without considering another could diminish the desirability of each to users. It is recognised that there are significant political and economic barriers to managing private business enterprises, even if the aim is to create a more socially attractive outcome. This is one important dimension distinguishing between private shopping malls and public streets.

\section{Conclusion}

This research examined public seating placement and arrangements to find how they are associated with people's stationary and social activities. We were also interested to understand any differences or similarities in seating preference between people from the four main ethnic groups in New Zealand. The principal conclusions correspond well with theories linking behaviour to spatial design characteristics. The findings confirm the important role businesses play in stimulating use of public seating. Benches should be located to provide visual access to activities, but somewhat separated from traffic and crowds. The study found that seating preferences of the four ethnicities are in many ways similar. In almost all conditions, people preferred to sit parallel to the footpath rather than perpendicular where they might feel vulnerable to those approaching from behind. While the preference for short and tall planting along the edge differed from one case to the other, in all conditions participants preferred to have landscaping along sidewalks. Therefore, urban designers should be mindful of how seating is located relative to other street amenities and physical artefacts. In addition to the type of businesses, the ways in which they manage and design their frontage can also influence preference and use. In general, participants favoured more ordered shop and café frontages compared to those that spread out onto the footpath. The type of activity (whether it is dynamic or sedentary) that seating looks out onto is important as well; people had lower preferences for seating that faces directly onto other sedentary activities, e.g. another bench or café activities. Figure 18 shows the characteristics of preferred seating situations.

There were no differences between ethnic groups in their preferences for seating arrangement types while seated alone. However, preferences for different seating arrangements did vary between ethnic groups and this could be traced to the sizes of groups. Figure 19 shows the type of 


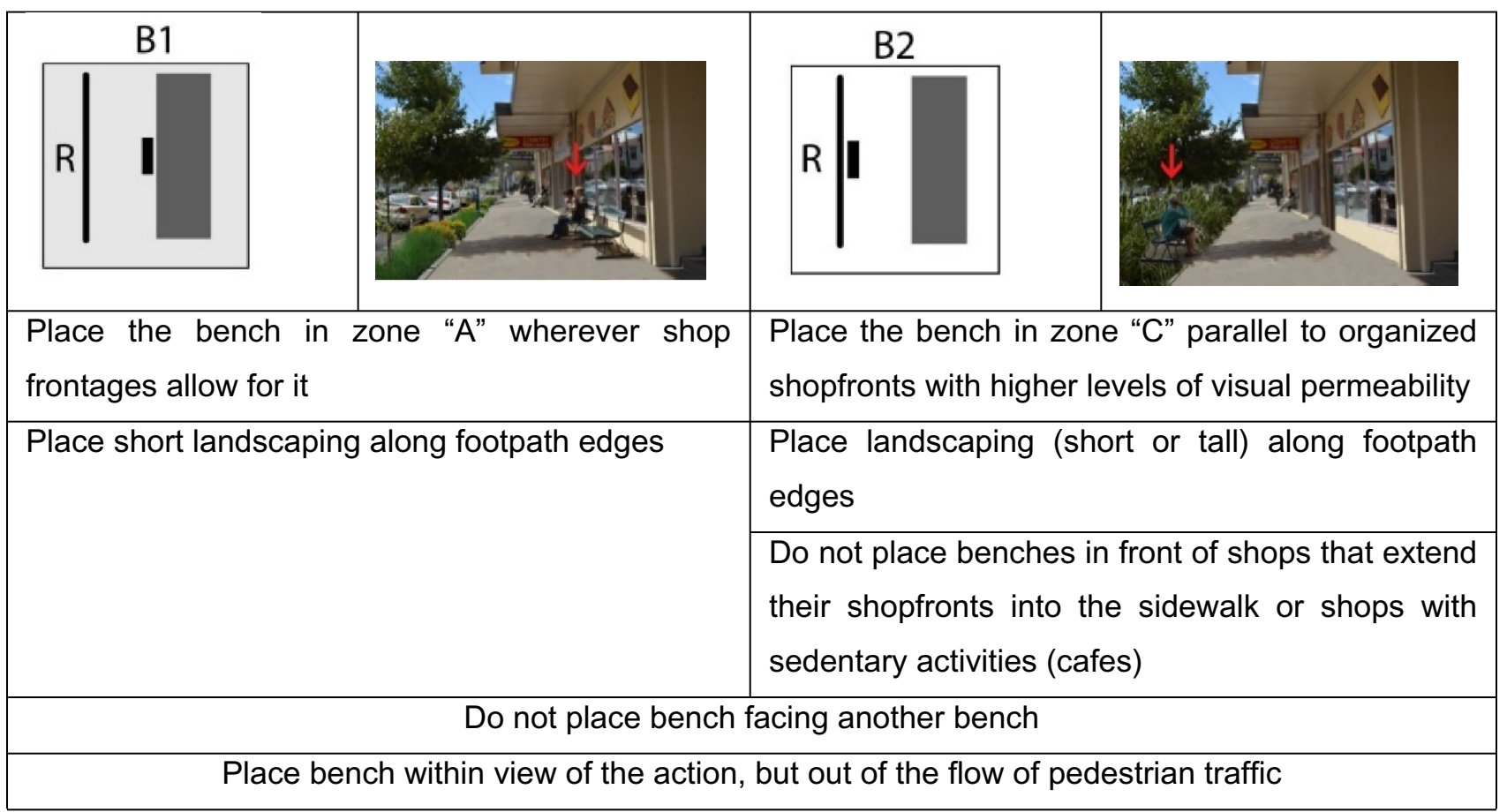

Fig. 18 Characteristics of preferred seating situations

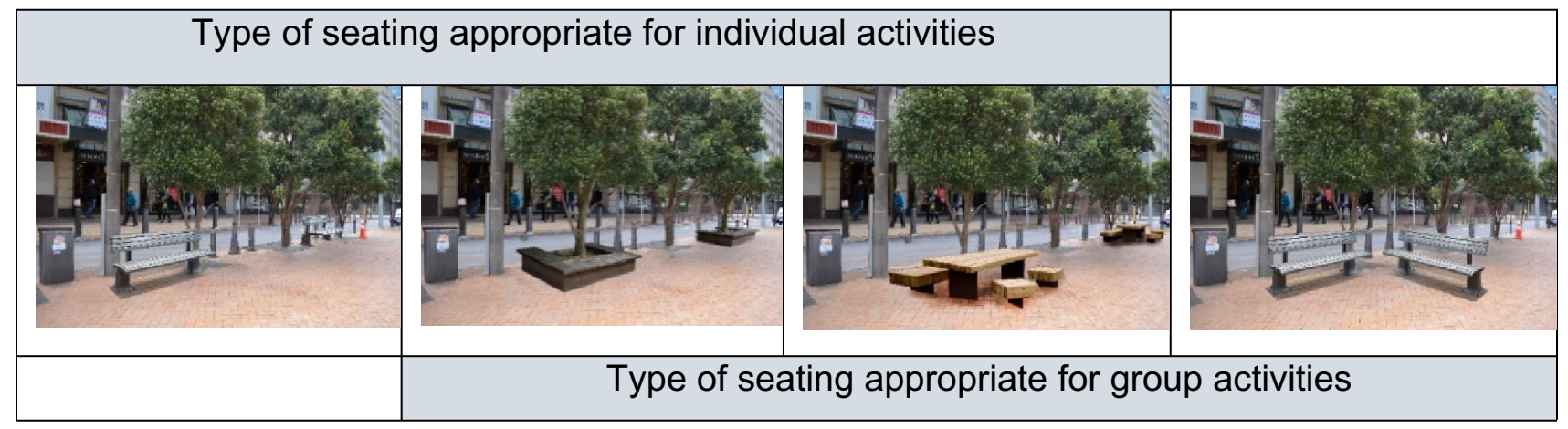

Fig. 19 Recommended seating arrangements for both individual and group activities (numbers of each seating arrangement type depends on the socio-cultural characteristic of street users)

seating arrangements that could be placed on sidewalks in order to accommodate both group and individual activities. Seating in socio-fugal, linear arrangements should be placed in an appropriate distance from each other so that they can encourage individual use. The socio-fugal seating type and the seating arrangement around a table is preferred for the leisure and social activities of individuals and groups. Moreover, placing seating with a 90-deg orientation on footpaths would be beneficial among a diverse range of cultures for social activities.

The paper makes the case for evidence-based research to inform the design of public spaces, including the most common - the sidewalks of public streets. Through empiric studies such as this the preferences of people from different ethnic cultural backgrounds can be identified. The decisions and choices urban planners and designers make on footpath furniture greatly influence users' preference and use. Design that seeks to support these preferences, particularly when they overlap between groups can help public spaces become more sociable for a wider range of cultural backgrounds.

\section{References}

Appleton, J. 1975. The Experience of Landscape. London: Wiley. 
Appleyard, D. 1981. Livable Streets. Los Angeles: University of California Press.

Bosselmann, P. 2008. Urban Transformation: Understanding City Design and Form. Washington, DC: IslandPress.

Carmona, M. 2019. Principles for Public Space Design, Planning to do Better. Urban Design International 24: 47-59.

Carmona, M., C. De Magalhaes, and L. Hammond. 2008. Public Space: The Management Dimension. London: Routledge.

Carmona, M., S. Tiesdell, T. Heath, and T. Oc. 2010. Public Places, Urban Spaces, 2nd ed. Oxford: Elsevier Ltd.

Carr, S., M. Francis, L. Rivlin, and A. Stone. 1992. Public Space. Cambridge: Cambridge University Press.

Cohen, D.A., T.L. McKenzie, A. Sehgal, S. Williamson, D. Golinelli, and N. Lurie. 2007. Contribution of Public Parks to Physical Activity. American Journal of Public Health 97 (3): 509-514.

Fernando, N.A. 2006. Open-Ended Space: Urban Streets in Different Cultural Contexts. In Loose Space: Possibility and Diversity in Urban Life, ed. K.A. Franck and Q. Stevens, 54-72. New York: Routledge.

Francis, M. 1987. The Making of Democratic Streets. In Public Streets for Public Use, ed. A. Vernez-Moudon, 23-39. New York: Columbia University Press.

Gehl, J. 1987. Life Between Buildings Using Public Space. New York: Van Nostrand Reinhold.

Gjerde, M. 2011. Visual Evaluation of Urban Streetscapes: How do Public Preferences Reconcile with Those Held by Experts? Urban Design International 16: 153-161.

Hall, E.T. 1966. The Hidden Dimension. Garden City: Anchor Books.

Hass-Klau, C., G. Crampton, C. Dowland, and I. Nold. 1999. Streets as Living Space: Helping Public Places Play Their Proper Role. London: Landor.

Hou, J. 2013. Your Place and/or My Place. In Transcultural Cities: Border-Crossing and Placemaking, ed. J. Hou, 1-16. New York: Routledge.

Hutchinson, R. 1987. Ethnicity and Urban Recreation: Whites, Blacks, and Hispanics in Chicago's Public Parks. Journal of Leisure Research 19: 205-222.

Jacobs, J. 1961. The Death and Life of Great American Cities. New York: Vintage Books.

Jacobs, A. 1993. Great Streets. Cambridge: The MIT Press.

Joardar, S.D., and J.W. Neill. 1978. The Subtle Differences in Configuration of Small Public Spaces. Landscape Architecture 68: $487-491$

Kaye, S.M., and M.A. Murray. 1982. Evaluations of an Architectural Space as a Function of Variations in Furniture Arrangement, Furniture Density, and Windows. Human Factors: The Journal of the Human Factors and Ergonomics Society 24: 609-618.

Kohn, M. 2004. Brave New Neighborhoods: The Privatization of Public Space. London: Routledge.

Lang, J. 1987. Creating Architectural Theory: The Role of the Behavioral Sciences in environmental design. New York: Van Nostrand Reinhold.

Lesan, M., and M. Gjerde. 2015. Management of Business Activities Along Streets; an Often Neglected Aspect of Urban Design. Paper Presented at the Living and Learning: Research for a Better Built Environment: The 49th International Conference of the Architectural Science Association, The University of Melbourne.

Loukaitou-Sideris, A. 1995. Urban Form and Social Context: Cultural Differentiation in the Uses of Urban Parks. Journal of Planning Education and Research 14 (89): 89-102.

Madanipour, A. 2004. Marginal Public Spaces in European Cities. Journal of Urban Design 9 (3): 267-286.

Main, B., and G.G. Hannah. 2010. Site Furnishings: A Complete Guide to the Planning, Selection and Use of Landscape Furniture and Amenities. Hoboken: Wiley.
Mehta, V. 2006. Lively Streets: Exploring the Relationship Between Built Environment and Social Behavior. (Doctor of Philosophy). University of Maryland, College Park, USA.

Mehta, V. 2013. The Street: A Quintessential Social Public Space.

Mulgan, G., G. Potts, J. Audsley, M. Carmona, C. De Magalhaes, L. Sieh, and C. Sharpe. 2006. Mapping Value in the Built Urban Environment: A Report to the Commission for Architecture and the Built Environment ( $C A B E$ ). London: The Young Foundation.

Ostmond, H. 1957. Function as the Basis of Psychiatric Ward Design. Mental Hospitals 8: 23-30.

Parham, S. 1992. Conviviality by Design: Gastronomic Strategies for Australian Cities. Urban Futures: Ideas for Australian Cities 2 (2): $25-35$.

Parham, S. 2012. Market Place: Food Quarters, Design and Urban Renewal in London. New Castle Upon Tyne: Cambridge Scholars Publishing.

Pearson, D. 2012. Ethnic Inequalities - Occupation and Education [Online]. Te Ara - the Encyclopedia of New Zealand. http://www. TeAra.govt.nz/en/ethnic-inequalities/. Accessed 17 Sept 2014.

Porta, S., and R. Luciano. 2005. Linking Urban Design to Sustainability: Formal Indicators of Social Urban Sustainability Field Research in Perth, Western Australia. Urban Design International 10: 51-64.

PPS. 2008a. Have a Seat: Movable Chairs or Benches? [Online]. Project of Public Space. http://www.pps.org/reference/movable-seati ng/. Accessed 14 Aug 2014.

PPS. 2008b. A Primer on Seating [Online]. http://www.pps.org/refer ence/generalseating/. Accessed 20 Nov 2015.

Pugalis, L. 2009. The Culture and Economics of Urban Public Space Design: Public and Professional Perceptions. Urban Design International 14: 215-230.

Rapoport, A. 1982. The Meaning of the Built Environment: A Nonverbal Communication Approach. Beverly Hills: Sage Publications.

Rapoport, A. 2005. Culture, Architecture, and Design. Chicago: Locke Science.

Rapoport, A. 2008. Some Further Thoughts on Culture and Environment. Archnet-IJAR 2 (1): 16-39.

Shaftoe, H. 2009. Convivial Urban Spaces: Creating Effective Public Places. London: Sterling.

Thomas, D.R. 1991. The Demise of Public Space. In Town Planning Responses to City Change, ed. V. Nadin and J. Doak, 209-224. Aldershot: Avebury.

Thompson, S.M. 2003. Digestible Cultural Difference: The Use of Food to Claim Space in the Public Realm. Paper presented at the National Planning Congress: Leading Diversity, 31 March-2 April, Adelaide, South Australia.

Varna, G., and S. Tiesdell. 2010. Assessing the Publicness of Public Space: The Star Model of Publicness. Journal of Urban Design 15 (4): 575-598.

Velden, B., D. Reeves. 2010. Intercultural Public Spaces. Paper Presented at the International Planning Conference, Christchurch, New Zealand.

Whyte, W.H. 1980. The Social Life of Small Urban Spaces. Washington, DC: The Conservation Foundation.

Whyte, W.H., and P. Underhill. 1988. City: Rediscovering the Center. New York: Doubleday.

Zambonelli, V. 2013. Brazilian Restaurants and the Transcultural Making of Place in Tokyo, Japan. In Transcultural Cities: Border Crossing and Placemaking, ed. J. Hou. New York: Routledge.

Publisher's Note Springer Nature remains neutral with regard to jurisdictional claims in published maps and institutional affiliations. 